Florida International University

FIU Digital Commons

FIU Electronic Theses and Dissertations

University Graduate School

6-22-2010

\title{
The Relationship Between Prekindergarten Social and Emotional Development and Academic Success among Hispanic Children from Low- Income Families
}

Christina More Muelle

Florida International University, cmoremuelle@att.net

DOI: $10.25148 /$ etd.FI10080404

Follow this and additional works at: https://digitalcommons.fiu.edu/etd

Part of the Curriculum and Instruction Commons, and the Educational Psychology Commons

\section{Recommended Citation}

Muelle, Christina More, "The Relationship Between Prekindergarten Social and Emotional Development and Academic Success among Hispanic Children from Low-Income Families" (2010). FIU Electronic Theses and Dissertations. 229.

https://digitalcommons.fiu.edu/etd/229 


\title{
FLORIDA INTERNATIONAL UNIVERISTY
}

Miami, Florida

\section{THE RELATIONSHIP BETWEEN PREKINDERGARTEN SOCIAL AND \\ EMOTIONAL DEVELOPMENT AND ACADEMIC SUCCESS AMONG HISPANIC CHIDREN FROM LOW-INCOME FAMILIES}

\author{
A dissertation submitted in partial fulfillment of the \\ requirements for the degree of \\ DOCTOR OF PHILOSOPHY \\ in \\ CURRICULUM AND INSTRUCTION
}

by

Christina More Muelle

2010 


\section{To: Interim Dean Delia C. Garcia College of Education}

This dissertation, written by Christina More Muelle, and entitled The Relationship Between Prekindergarten Social and Emotional Development and Academic Success among Hispanic Children from Low-Income Families, having been approved in respect to style and intellectual content, is referred to you for judgment.

We have read this dissertation and recommend that it be approved.

Leonard Bliss

Angela Salmon

Laura Dinehart

Charles Bleiker, Major Professor

Date of Defense: June 22, 2010

The dissertation of Christina More Muelle is approved.

Interim Dean Delia C. Garcia College of Education

Interim Dean Kevin O'Shea

University Graduate School

Florida International University, 2010 
(C) Copyright 2010 by Christina More Muelle

All rights reserved. 


\section{DEDICATION}

I dedicate this dissertation to my children, Adrian and Andrea, whose arrival into this world distracted me away from my studies. It is for them that I finish proudly, showing them that when they set their minds on a goal, anything can be accomplished!

I also dedicate this dissertation to all the children who have walked through the doors of my classroom and changed my life and heart. I hope that they have learned as much from me as I have learned from them. May they continue to flourish and shine brightly for the rest of their lives. 


\section{ACKNOWLEDGMENTS}

First and foremost I would like to thank my family. My husband, Alek, whose words of wisdom allowed me to get back on track when I strayed from the writing path. My parents, Maria and Armando, without them I would never have finished writing this dissertation. My mom's many hours of babysitting and encouragement to finish this chapter of my life allowed me to focus and complete my lifelong dream of receiving a doctorate degree. My in-laws, Lilly and Gus, thanks for cooking great food for your grandkids and giving me extra time to spend at the library writing.

Next I would like to thank my dissertation committee for entering into this adventure with me and delivering constructive criticism in order to help me become a better researcher and writer. Dr. Bleiker, thank you for the endless hours of editing, introducing me into the world of academia by allowing me to teach classes, write grants and work on research projects. Dr. Bliss, thank you for sitting with me as I showed you my SPSS analysis and commenting on my interpretations of the results. Dr. Dinehart, thank you for your patience as you reviewed my final drafts and taught me how to connect my thoughts and put them in writing. Dr. Salmon, thank you for your commentaries on the final draft of my dissertation and all your input. 


\author{
ABSTRACT OF THE DISSERTATION \\ THE RELATIONSHIP BETWEEN PREKINDERGARTEN SOCIAL AND \\ EMOTIONAL DEVELOPMENT AND ACADEMIC SUCCESS AMONG HISPANIC \\ CHIDREN FROM LOW-INCOME FAMILIES \\ by
}

Christina More Muelle

Florida International University, 2010

Miami, Florida

Professor Charles Bleiker, Major Professor

Social and emotional development has been considered an important factor in child development which has been placed at the end of the learning spectrum due to high stakes testing. Social and emotional development consists of the relationships an individual has with others, the level of self-control, and the motivation and perseverance a person has during an activity (Bandura, 1989). This study examined the relationship between Hispanic children's prekindergarten social and emotional development and their academic success.

Hispanic children from a large southeastern city whose parents were receiving subsidized child-care were followed from their prekindergarten year through third grade $(\mathrm{N}=1,978)$. Several hierarchical regressions were run to determine the relationship between children's social and emotional development, during their prekindergarten year using the DECA (Devereaux Early Childhood Assessment), and the their academic success, as measured by kindergarten through third grade end of the year reading and 
mathematics academic grades, second grade SAT (Stanford Achievement Test) scores, and third grade FCAT (Florida Comprehensive Assessment Test) and NRT (Norm Referenced Test) scores. Hierarchical regressions were conducted for each grade and subject in order to control for demographics and prior achievement.

The results of this study revealed that for Hispanic children from low-income families, the best predictor for academic success was the children's prior academic achievement. Social and emotional development showed no significant predictive value for the third grade criterion variables as well as end of the year academic grades in second grade and kindergarten reading. Evidence did suggest that for first grade end of the year academic grades and kindergarten math, social and emotional development had a small predictive value.

Further research must be conducted as to why social and emotional development, after controlling for demographics and previous academic achievement, bears such a small predictive value when it is clear that many professionals feel it is the most important factor for school readiness. 


\section{TABLE OF CONTENTS}

\section{CHAPTER}

PAGE

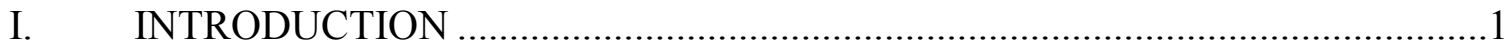

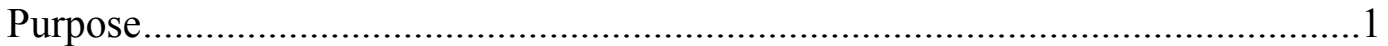

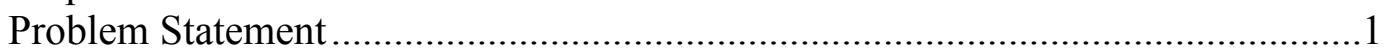

Research Question and Hypothesis.................................................................4

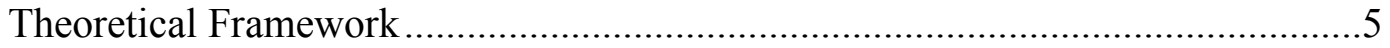

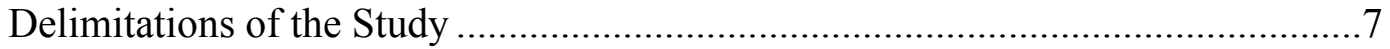

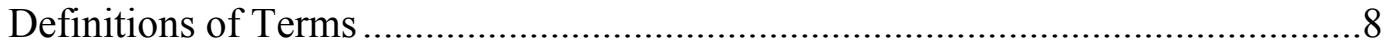

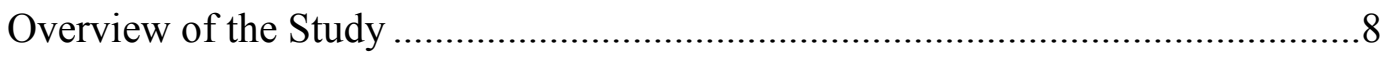

II. REVIEW OF THE LITERATURE ........................................................... 10

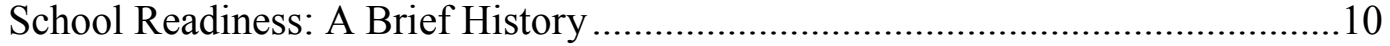

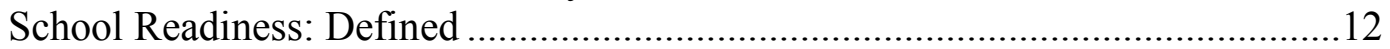

Social and Emotional Development and Academic Achievement .......................20

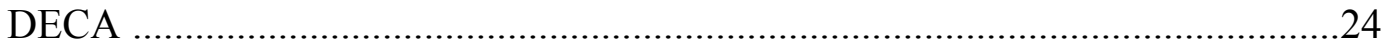

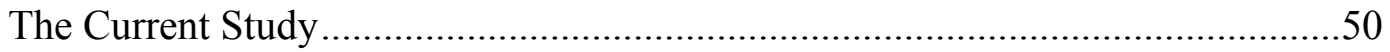

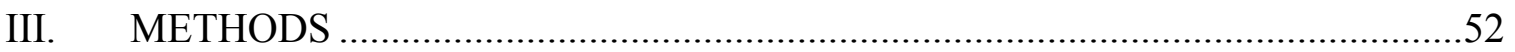

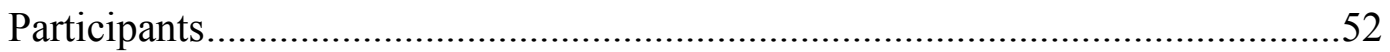

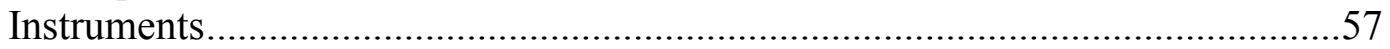

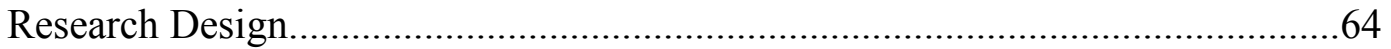

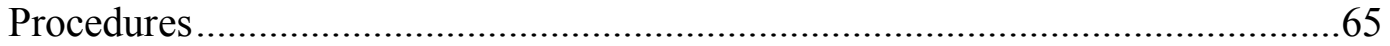

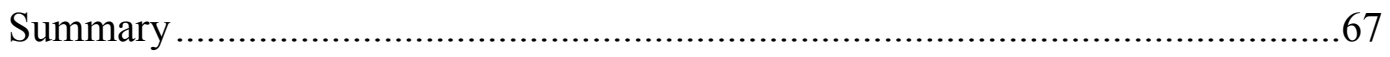

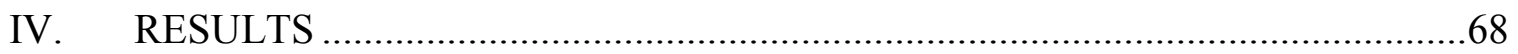

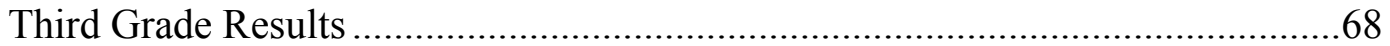

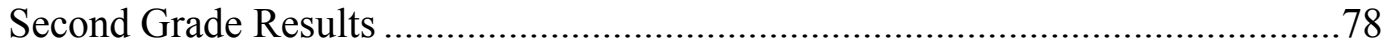

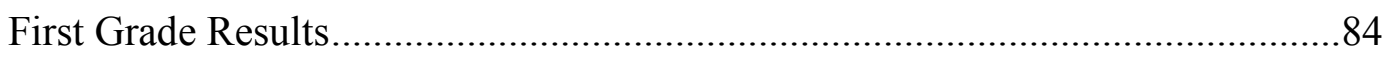

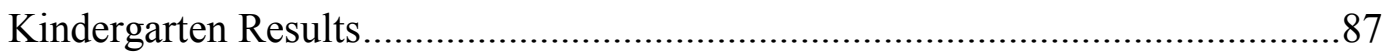

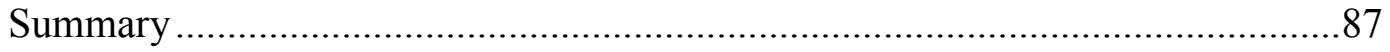

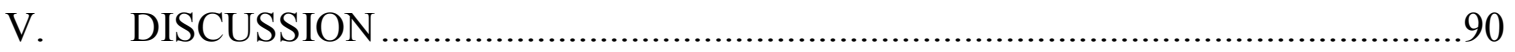

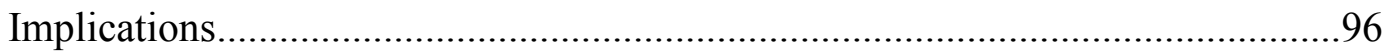

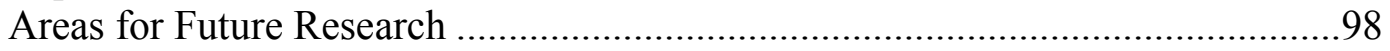

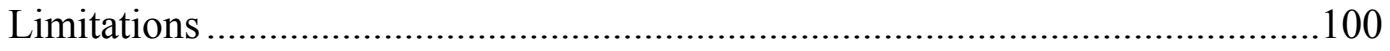

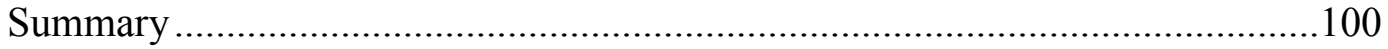

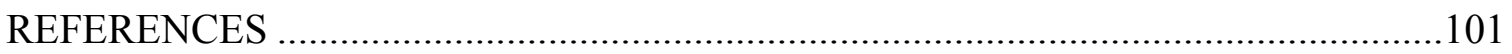

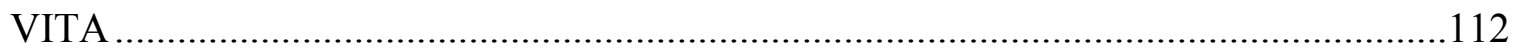




\section{LIST OF TABLES}

TABLE

PAGE

1. Hierarchical Regressions for Variables Predicting Third Grade End of the Year Academic Grades

2. Hierarchical Regressions for Variables Predicting Third Grade NRT Scores

3. Hierarchical Regressions for Variables Predicting Third Grade FCAT Scores .76

4. Hierarchical Regressions for Variables Predicting Second Grade End of the Year Academic Grades

5. Hierarchical Regressions for Variables Predicting Second Grade SAT Scores

6. Hierarchical Regressions for Variables Predicting First Grade End of the Year Academic Grades

7. Hierarchical Regressions for Variables Predicting Kindergarten End of the Year Academic Grades .88

8. Correlations Between DECA Factors and Academic Achievement .93 


\section{CHAPTER I}

\section{INTRODUCTION}

Current trends require that children entering kindergarten know how to work independently, follow classroom rules, and demonstrate prosocial skills. Studies have indicated that kindergarten teachers feel that social skills are more important for a child's development and school readiness than academic skills (Johnson, Gallagher, Cook, \& Wong, 1995; Lin, Lawrence, and Gorrell, 2003; Piotrkowski, Botsko \& Matthews, 2000; Wesley \& Buysse, 2003). Kindergarten teachers expect their students to be able to work independently, follow classroom rules, demonstrate positive social skills, play well with others, and communicate their feelings in order to be ready for school and succeed in kindergarten (Johnson, Gallagher, Cook \& Wong, 1995; Lin, Lawrence, \& Gorrell, 2003; Piotrkowski, Botsko, \& Matthews, 2000; Wesley \& Buysse, 2003).

\section{Purpose}

This study examined the social and emotional skills of impoverished Hispanic prekindergarten children and the extent to which those skills predict their academic success in third grade. If the connection can be made between the factors that make up social and emotional development (i.e., attachment, self-control, and initiative) and academic success, then kindergarten teachers' views of readiness will be valid. The purpose of this study was to investigate how the social and emotional development of young, poor, Hispanic children before they enter kindergarten predicts academic success.

\section{Problem Statement}

As the United States continues to emphasize high stakes testing in the public school system, it is becoming evident that an academic based curriculum is being pushed 
down through the grades. What once was a historically social curriculum in kindergarten, founded by Fredriech Froebel, is today very similar to what was previously considered first grade (Miller \& Almon, 2009; Shepard, 1997). Children are expected to sit at desks or tables and complete worksheets in silence while the teacher walks around to make sure everyone is on task. The kindergarten curriculum has been pushed down to preschool and prekindergarten, where the children are expected to recite letters and sounds as well as rote count to 20 (Miller \& Almon, 2009).

Teaching children in this regimented way, not only takes the place of a more holistic, social-emotionally centered curriculum, it also hinders the development of early social skills the children may be developing (Miller \& Almon, 2009). When the classroom is "other regulated" and controlled to a great extent, children have scant opportunities to learn and practice these valuable behavioral skills. This creates a common situation of children starting kindergarten who do not know how to socially interact with others or control their own behavior.

Goals 2000: Educate America Act (1994) stated as its first goal that, "By the year 2000, all children will start school ready to learn." While school readiness had long been a factor in educational research, this goal began a new surge of research dealing with school readiness, early childhood education, and what it really means.

School readiness can be defined in many ways. Some believe it is the relationship between social development and environmental factors in the schools (May \& Kundert, 1997). Others feel that school readiness means children need to be ready for school and ready to learn (Carlton \& Winsler, 1999). Children learn appropriate skills needed to succeed in the school environment. In order to learn these skills children need to feel that 
they have developed positive and reciprocal friendships in order to have an easier transition from preschool to kindergarten (Ladd, Koshenderfer, \& Coleman, 1996). They must have social interactions within their school environment and the interactions must be positive ones.

The Devereux Early Childhood Assessment (DECA) is widely used throughout the United States as a measure of social and emotional development because it focuses on children's social and emotional strengths rather than weaknesses (LeBuffe \& Shapiro, 2004; Rosas, Chaiken, \& Case, 2007). It attempts to avoid negative reinforcers by creating a profile of the social and emotional skills a child has and is lacking. This profile is then used to work on the skills the child needs by rewarding the positive behavior as opposed to punishing the negative ones (LeBuffe \& Shapiro, 2004). Other assessments such as the Behavioral and Emotional Rating Scale (Epstein, 1998) and the Child and Adolescent Needs and Strengths (Lyons, Griffin, \& Fazio, 1999) provide strength based assessments but not for preschool aged children or assess mental health challenges which are not strength based. The DECA is the only social and emotional assessment to focus on the strengths of children in preschool (LeBuffe \& Shapiro, 2004). Miami-Dade County Public Schools currently uses the DECA in order to assess the social and emotional development of preschool children.

While developing the DECA, LeBuffe and Shapiro (2004) conducted a factor analysis in order to find how the items related to research on protective factors, also called resilience. The items loaded into three factors. Based on the items, LeBuffe and Shapiro were able to label the factors as attachment, initiative and self-control. However, these factors seem to be highly correlated when further research revealed that 10 of the 
27 items loaded on more than one factor (Jaberg, Dixon, \& Weis, 2009). There are children who lack these protective factors and fall into a fourth factor labeled as behavioral concerns. These children need assistance in developing protective factors in order to overcome negative life experiences (LeBuffe \& Naglieri, 2009)

This study examined the social and emotional skills of prekindergarten Hispanic children and the ability to predict long-term academic success from these skills. Hispanics are one of the fastest growing populations in the United States (U.S. Census Bureau, 2009). Given that many Hispanics enter school as English Language Learners (ELL), may have recently immigrated to the U.S., and are more likely than not to be struggling with economic hardship, young Hispanic students represent a challenge to the public school system (Dinan, 2006). On the positive side, this group represents the tremendous potential and energy that new groups of immigrants bring to their adoptive countries (Kaiser \& Rasminsky, 2003). Not enough is known about how social and emotional development is connected with specific academic outcomes for this specific population of children. It is important to understand these factors and the implications for teachers in order to improve the academic success of Hispanic children.

\section{Research Question and Hypothesis}

This study set out to answer one main research question:

Research Question: Does the DECA, after controlling for demographics and previous academic achievement, predict academic success among Hispanic children from lowincome families? 
Hypothesis: The DECA, after controlling for demographics and previous academic achievement, will predict academic success among Hispanic children from low-income families.

\section{Theoretical Framework}

Social and emotional development is typically divided into three main areas: attachment, initiative and self-control, also known as self-regulation. John Bowlby and his protégé Mary Ainsworth (1991) took one behavioral component of the FreudEriksonian framework, attachment, and developed a comprehensive theory of how children learn to bond with others in their world. Bandura (1977), the father of social learning theory, helped develop the concepts of self-regulation, or self-control, in children's social development. Ford (1992) and Bandura (1989) then defined the third aspect, initiative, as an interaction between self-control and attachment.

Children need a secure base to explore the world around them. In most cases, this secure base is an attachment figure such as a mother, father or other primary caregiver. Babies whose mothers' responsiveness helped them attain their goals, developed confidence in themselves to control what happens to them (Bell \& Ainsworth, 1972). Further, children who have more secure relationships with their mothers performed higher on academic achievement tests than children with less secure relationships (Burchinal, Peisner-Feinberg, Pianta, \& Howes, 2002). Attachment may be culturally defined in that children experience a discontinuity between their parents' child-rearing beliefs and practices and those of the child care environment (Bronfenbrenner \& Morris, 1998). This can cause confusion in the child and effect a child's development. Some cultures foster inappropriate attachment in which children have severe separation anxiety 
and cannot leave their parents' side, while other cultures encourage children to explore their world knowing that their parents will be there when they return (Kaiser \& Rasminsky, 2003).

Bandura (1986) observed the way children used cognition in their social experiences and how cognitive operations influenced the way children develop and behave. Self-regulation is the process in which a person controls his or her own behavior through internal executive functions. Children develop their own standards or ideas about behaviors that are positive or negative and these ideas are formed from the responses they receive from adults (Vygotsky, 1978). Children who were able to regulate their actions and show cognitive control were shown to have greater success in school as measured by better grades in first grade, showed greater interest in school work and more concentration on a task (Normandeau \& Guay, 1998). According to Bandura (1992), self-regulation or self-control can be taught. Children first begin to regulate their behavior through an external locus of control. The external locus of control can be a parent, teacher or other caregiver. Children regulate their behavior based on a system of rewards and consequences. They act in certain ways in order to receive a reward or to not receive a consequence or punishment. As children begin to mature they begin to internalize these behaviors and begin to act as they were taught without receiving the reward. Children who demonstrate self-control have reached a point in which they have developed an internal locus of control and no longer need an adult to control their behavior (Bandura, 1992).

Initiative is defined as a psychological feature that entices a person to achieve a desired goal (LeBuffe \& Naglieri, 1998). The end result or goal is what is allowing the 
person to act or stay motivated. It gives reason and purpose for a person's direction and behavior. It is a more complex psychological factor that includes motivation, persistence, concentration and decision making (Aber \& Allen, 1987; Bandura, 1992, 2006; Bandura \& Mischel, 1965; Patterson \& Mischel, 1975; Turner \& Johnson, 2003). Children who have high levels of initiative have an increased level of attention and are able to control their effort towards academic tasks, which in turn increases their academic achievement (Chang \& Burns, 2005).

\section{Delimitations of the Study}

This study is delimited by only focusing on Hispanic children who receive subsidized childcare in one large urban city. This population limits generalizing the results of the study across other racial, ethnic and socioeconomic groups because these children have parents with a low socioeconomic status, reside in only one specific city in the United States, and are Hispanic. However, is should be noted that there was not enough information available in the dataset in order to distinguish the Hispanic subgroups from each other. Therefore it is important to note that the results from this study may not be used to generalize the results to the entire Hispanic population in the United States.

A second delimitation of this study is the data collection process. The data were part of a large scale grant received by a research university located in the southeastern part of the United States. This study is a secondary data analysis because the data were not collected directly by the researcher. 


\section{Definition of Terms}

Initiative. A child's ability to do things for him/herself, to keep trying when unsuccessful, and the eagerness to try new things independently (LeBuffe \& Naglieri, 1998).

Self-control. A child's ability to express his or her emotions appropriately, share with other children, demonstrate patience, and handle frustration (LeBuffe \& Naglieri, 1998).

Attachment. A long standing relationship between a child and significant adults such as parents or caregivers (LeBuffe \& Naglieri, 1998).

$D E C A$. Devereux Early Childhood Assessment - measures social and emotional factors (LeBuffe \& Naglieri, 1998).

FCAT. Florida Comprehensive Achievement Test - A criterion referenced test in reading and math used to measure progress in the Sunshine State Standards (Florida Department of Education [FDOE], 2007)

SAT. Stanford Achievement Test - A standardized test used to measure knowledge in reading and math (Harcourt Brace, 2003)

Prekindergarten. A class or educational program which precedes kindergarten that is typically for children 3 and 4 years old (Magnuson, Meyers, Ruhm, \& Waldfogel, 2004).

Overview of the Study

Chapter 2 includes various definitions of school readiness as well as what prekindergarten and kindergarten teachers typically view as the essential skills needed in order to be ready to succeed in school. Research regarding initiative, self-control and 
attachment is reviewed to show the relationship between social and emotional development and academic success. Chapter 3 is the description of the research design, methods, participants and procedures of this study. Chapter 4 contains the results of the study based on the research questions and data analysis. Chapter 5 incorporates the findings of the study and creates a relationship between this study and previous research. It also offers ideas for future studies and implications for early childhood educators. 


\section{CHAPTER II}

\section{REVIEW OF THE LITERATURE}

\section{School Readiness: A Brief History}

School readiness as a concept has been around since the beginning of formal early childhood education in the United States (Beatty, 1995). But this concept, that preschool serves primarily to socialize children and prepare them for the rigors of formal education, has resurfaced at different times in our history (Janus \& Offord, 2007). During the 1960's the Head Start Program was conceived of as primarily a "readiness" program for disadvantaged children who were thought to lack basic skills and knowledge that would allow them to take advantage of formal education (Zigler,1995; Zigler, 1999). More recently, this concept has been expanded to identify the importance of readiness as a necessary component to reform the educational system in the United States. This latest push for school readiness arose partly out of the efforts to rethink and reform a public school system that was showing signs of aging after almost a hundred years in existence.

The mathematics and science international comparisons (TIMSS) uncovered real weaknesses in the preparation of American students when compared to students in other industrialized nations (Harmon, et al. 1997). In April 1983, the report A Nation at Risk was presented to the Secretary of Education. In it, the Commission, set forth by President Reagan, stated the major problems with the education that children are receiving in the United States. The report concluded that, as a society, the objective was to develop children's talents to their full potential starting in early childhood. Early childhood was being reconceived, not as a period for social interaction and play, but as the first step in 
improving the education of a nation. This led to a greater focus on academic instruction and a de-emphasis on traditional early childhood practices (Elkind, 2001).

Continuing on in the 1990's, the Goals 2000: Educate America Act (approved by the House of Representatives in March 1994 and signed by President Clinton) further codified the nation's push for earlier academic instruction. This act presented eight goals to be accomplished by the year 2000. The first goal states "By the year 2000, all children will start school ready to learn." This goal did not define what "ready" meant, but began a resurgence of research dealing with school readiness and early childhood education focused on five dimensions that were considered to be central to school readiness: a) physical well-being and motor development, b) language use, c) cognition and general knowledge, d) social and emotional development, and e) approaches to learning. In 1999, the State of Florida decided that it wanted to do more than provide minimal care. It passed the School Readiness Act (SB 411), which created independent oversight coalitions throughout the state (Davis, 2005). These School Readiness Coalitions were charged with improving the quality of childcare in the system of subsidized care by competitively bidding for services, assessing children's outcomes, and implementing interventions based on documented need.

Following these initiatives, President George W. Bush signed the No Child Left Behind Act of 2001. This law held states accountable for the progress of their students leading to state mandated tests beginning in third grade. This national accountability movement had the effect of focusing early childhood programs on academic skills at the expense of traditional socialization skills (Janus \& Offord, 2007). The push for academics in government funded early childhood education was accompanied by the 
school readiness assessment movement. By 2005, all fifty states had implemented some type of school readiness assessment (Miller \& Almon, 2009). These assessments typically included academically related items like name writing, letter knowledge, counting and shape recognition, but did little to assess the social emotional development of the child.

\section{School Readiness Defined}

School readiness has been portrayed as the development of skills related to language, literacy, numeracy as well as other cognitive skills, while others have portrayed school readiness as a combination of not only cognitive skills but also physical well being and social competence (Thompson \& Raikes, 2007). Questions remain as to whether it is appropriate to hold all children to the same standards of school readiness or whether school readiness differs from children of different ethnic, racial and socioeconomic backgrounds. Implications for assessing school readiness emerged from the alternative views of readiness which suggest that assessments may include classroom observations, standardized tests, or work portfolios (Thompson \& Raikes, 2007). These definitions of school readiness are important to clarify the skills young children need in order to be prepared for school. They are also important for describing the role of social and emotional development on academic success. School readiness can be looked at as having two separate entities (Carlton \& Winsler, 1999). Children can be ready for school and children can be ready to learn. A child who is ready for school is one who can be successful in a school environment. A child who is ready to learn is one who is able to learn some specific task or concept. 
Several views of school readiness have emerged at different times in the past. One definition of school readiness describes readiness as a quality that resides within the child. A child becomes ready for school through maturity alone. This maturationist view of development, suggested that waiting was all that was necessary for children to become ready (Gesell \& Ilg, 1949). The empiricist/environmentalist view takes into account behaviors, skills, and individual traits of each child that are considered the foundations of school success (Meisels, 1999). This view suggests that the type of experience the child has in the early years makes a difference in how ready or not a child is to begin schooling. A third more recent view, social constructivism, has evolved which considers not only a child's readiness to learn - both in maturation and experience - but the school's readiness for the child. (May \& Kundert, 1997). Another view of school readiness, suggests there is a disconnect between the home environment and the schools which causes early school difficulties, not problems with children (Delpit, 1995). This view proposes that culturally insensitive schools do not teach to children in ways that are familiar, are likely to underestimate their abilities, and increase the likelihood of them being referred for special attention. Finally, the interactionist view (Meisel, 1998) takes a middle ground, proposing that it is both the environment and the institution that causes children to do poorly in the early grades. This view suggests that schools need to adapt to meet the needs of the always changing society, at the same time that children and parents need to adapt to the culture of schooling.

Teachers, past and present, have taken into account all these different views of school readiness as well as their own experiences while teaching young children. These experiences have led teachers to create their own concepts of skills children need in order 
to start school ready to learn. Johnson, Gallagher, Cook, and Wong (1995) examined teachers' perceptions of skills children need in order to be successful in their class. Kindergarten teachers in three southeastern school districts were surveyed. Surveys were mailed to over 250 teachers and 176 were returned. The teachers were asked to rate the importance each skill from five domains (gross motor, school readiness, fine motor, general knowledge, social and language) was for a child to have mastered by the time they started kindergarten. Then the teachers were asked to choose the five most important skills from each domain and the top ten essential skills, from any of the domains, a child needs to have before entering kindergarten.

Johnson et al. (1995) found that kindergarten teachers expected the students to enter kindergarten being able to be feed, toilet, and work independently, engage in conversation and use sentences when speaking, follow classroom rules, separate from their caregiver, say their birthday, name the colors, and spell their first name as well as many other skills. Of the 149 skills teachers rated as necessary for kindergarten, 22 skills were rated by teachers as most important. Seven were from the social domain, five were language, four were gross motor and three were from fine motor and academic domains. The findings from this study revealed that teachers felt social and language skills were the most important for school readiness while academic skills lagged behind. The results demonstrate that while kindergarten teachers felt academic readiness is important, social skills are more important for a child to be successful in school. These findings are similar to other studies on school readiness which have also found the importance of a child being socially and emotionally ready to start school (Lin, Lawrence, \& Gorrell, 
2003; McAllister, Wilson, Green, \& Baldwin, 2005; Piotrkowski, Botsko, \& Matthews, 2000; Wesley \& Buysse, 2003).

Kindergarten teachers of different ages and from different regions of the United States valued readiness skills differently (Lin, Lawrence, \& Gorrell, 2003). Over three thousand kindergarten teachers from the Early Childhood Longitudinal Study Kindergarten completed a self-administered questionnaire. The questionnaire consisted of three sections, the last dealing with school readiness. Only one question from this section was used as the dependent variable. The teachers were asked to rate the importance of 13 items from "not important to essential" (page 229). Four of the items dealt with academic expectation (names of colors and shapes, counts to 20, knows the alphabet, and uses a pencil) while the remaining items were related to social expectations. Teachers placed the most emphasis in order of importance on students' being able to say their needs and thoughts, not being disruptive, following directions, turn taking, being sensitive to others, and staying on task.

Younger teachers placed higher emphasis on academic readiness than older teachers. Teachers from the south had higher academic expectations than teachers from the rest of the country. Overall, the main finding was that kindergarten teachers as a whole felt that social skills were more important for a child's development and school readiness than academic skills. The teachers felt that the behavior of children within a group is related to their social skills and readiness for kindergarten (Lin, Lawrence, \& Gorrell, 2003). These findings are consisted with a study conducted ten years earlier in which kindergarten teachers also placed more emphasis on following directions, not being disruptive in class, and taking turns as opposed to other academic factors 
(Heaviside \& Farris, 1993). Teachers have been emphasizing the importance of social behavior in order to be ready for kindergarten, yet school systems across the country continue to focus preschool and kindergarten curriculum on academic factors. Teachers felt that if there is a greater emphasis on social factors during preschool and kindergarten, academic success will then follow (Lin, Lawrence, \& Gorrell, 2003).

Preschool and kindergarten teachers' beliefs about school readiness were compared in an urban school district in New York State (Piotrkowski, Botsko, \& Matthews, 2000). The teachers' beliefs were also compared to those of parents of the children in the school district. The city has a large number of Hispanic and Black families, $90 \%$ of whom receive free lunch. The district also has had and continues to have significant academic problems. Parents and teachers from preschools in the community and from public school prekindergarten and kindergarten were asked to participate in the study. Four hundred sixty-one parents, 46 preschool teachers, 6 prekindergarten teachers and 57 kindergarten teachers returned the survey that was distributed by mail or at the school. The importance of readiness resources that were assessed were based on the five dimensions stated in Goal 1 of the National Education Goals. The parents and teachers rated each item from the Community Attitudes on Readiness Skills (CARES) from not too important to absolutely necessary (Piotrkowski, Botsko, \& Matthews, 2000).

Parents and teachers agreed that the skills children need in order to be ready for school are playing well with others, communicating feelings, and emotional maturity. These skills were considered necessary while other skills such as self-care, motor skills, engagement, and interest were not as important. Despite ethnicity and education, parents 
had similar beliefs of school readiness. They also rated classroom related skills as more important than teachers. However, preschool teachers felt that academic knowledge was more important than kindergarten teachers. These findings show that both teachers and parents feel that social skills are the most important for a child to be ready and successful in school (Piotrkowski, Botsko, \& Matthews, 2000).

Parents have also addressed the issue of schools readiness by vocalizing their viewpoints on the skills their children need to possess in order to start school ready to learn and succeed. Focus groups, consisting of parents and professionals (teachers and principals) from several communities in North Carolina, were used to explore the beliefs of school readiness and provide in depth descriptions of what parents and professionals viewed as important in school readiness and the issues surrounding it (Wesley \& Buysse, 2003). The participants included 25 parents and 93 professionals from elementary public schools (32 prekindergarten teachers, 36 kindergarten teachers, and 25 principals).

Twenty focus groups were formed in five different communities and each group included at least one participant from each of the four categories stated above.

The majority of focus groups agreed that children need to be able to create healthy attachments with their parents and know that at the end of the day a parent will be there to pick them up (Wesley \& Buysse, 2003). The professionals (both teachers and principals) reported being torn between finding time to guide a child's social and emotional development and deliver academics required by the state. They also felt that teachers are evaluated based on how children perform academically and not what else is happening in the classroom. All the professionals felt that children should not be held to the same readiness factors because some children whose birthdays fall after the cut-off 
date to start kindergarten may be ready, children with disabilities may never be ready for school, and children whose English is not their first language may not be labeled as ready because they don't speak the language. Teachers felt a frustration between the educational philosophies they were taught in teacher preparation courses and what was being asked of them from the school system. "Prekindergarten teachers spoke of the importance of building children's confidence, stimulating their creativity, engaging their attention and being mindful of their curiosity related to various tasks" (Wesley \& Buysse, pages 357-358). Principals and kindergarten teachers felt that "ready children" also depended on a child's previous life experiences and gave an example of a child who entered kindergarten having had been read to most of his life where as another child did not even know how to hold a book because no one had ever read to him.

Parents felt that a child's first school experience should include teaching children how to learn in school as well as the actual academic portion. Parents also wanted children to get along with others, respect authority, have self-respect and be able to stand up for themselves (McAllister, Wilson, Green, \& Baldwin, 2005). If children do not know how to learn they way schools ask them, then they will not be able to academically perform (Wesley \& Buysse, 2003). Parents and prekindergarten teachers felt the kindergarten curriculum was too academic and students moving from a center-based program in prekindergarten were not ready for the rigorous academic program of kindergarten; which expected to students to sit quietly at their desks and perform drill and practice techniques. Professionals and parents also described concern with schools not being ready for children because they lacked sufficient facilities and an understanding of 
students' cultural backgrounds. They believed the kindergarten curriculum should be changed to a more developmentally appropriate one for five year olds.

Parents and teachers agreed that the skills children need in order to be ready for school include playing well with others, communicating feelings, and emotional maturity. These skills were considered absolutely necessary while other skills such as self-care and motor skills were not as important. Differences among the groups showed that while parents rated Basic Knowledge as absolutely necessary, kindergarten teachers rated these skills much lower than both the parents and preschool teachers. These findings show that both teachers and parents feel that social skills are important for a child to be ready and successful in school, while parents and preschool teachers placed greater emphasis on academic skills than kindergarten teachers. Parents feel that social and emotional skills are just as important as academic and cognitive skills in order for children to be ready to learn. Specifically, self-control was mentioned as being a major skill children need as stated by a parent, "if they know how to sit there and listen, then they are ready for school.”(McAllister, Wilson, Green, \& Baldwin, 2005, p. 620)

Social and emotional development becomes pertinent to school readiness if preparation for school includes cooperating with others, resolving conflicts, working in groups, and demonstrating self-control. However, if preparation for learning (academic success) is related to curiosity, self-confidence, creativity, and adaptability, then social and emotional development may impact the relationships of the skills necessary for school readiness (Thompson \& Raikes, 2007). All these definitions of school readiness take in account what is essential for children to succeed in school as well as establish a 
base for the overall goal of academic success in graduation, employment, citizenship and other goals society has for children (Thompson \& Raikes, 2007).

\section{Social and Emotional Development and Academic Achievement}

The extent to which social and emotional development predicts long-term academic achievement remains unclear. Some studies suggest that social and emotional development is not a predictor of academic achievement. Duncan et al. (2007) used 6 large scale longitudinal studies in order to examine how attention, socioemotional skills and school entry academics are associated with later school achievement. Two of those studies were nationally representative of United States children while another two were multisite studies of children in the United States. The other two studies focused on children from Canada and Great Britain respectively. All the data sets have attention, academic, and social and emotional assessments at school entry. The strongest predictors of later academic achievement were school entry math, followed by school entry reading and finally attention skills. Social and emotional skills showed no predictive value in later achievement, even among children who demonstrated high levels of behavior problems.

In an attempt to study the predictive value of motivation and self-regulation on academic success, Howes, Lange, Farran, and Boyles (2003) found that the child's academic ability from the previous year had the most predictive value over motivation and self-regulation. The participants of this study included 64 kindergartens, 43 whom were labeled at risk, and 63 second graders, 42 who were labeled at risk. Of the children who were labeled at risk, 64 were African American and the remaining were White, 
Asian or Hispanic. The children who were not at risk were comprised of 33 White children and 9 African American children.

In order to assess motivation, children were given the Young Children's Feelings about School assessment as well as a preference for a challenging task. Self-regulation was assessed using the Self-Regulation Test for children. The children also took the Peabody Picture Vocabulary Test-III (PPVT-III) in order to assess vocabulary. Achievement tests were administered in April. The kindergarten children were given the Test for Early Reading Ability and the Test for Early Math Achievement. The second grade children took the Peabody Individual Achievement test for mathematics and reading (Howes et al., 2003). Self-regulation showed no significance when used as a predictor for younger children's achievement and motivation showed no significance for second grade children. The strongest predictor of academic success for both the kindergarten and second grade students was the PPVT-III. When achievement scores of the students previous year was included in the regression model, those scores were showed the strongest predictive value (Howes et al., 2003).

Despite the results of these studies, other studies have begun to highlight the importance of social and emotional development on academic success. However, the majority of these studies have focused on the negative impacts of behavior problems and academic failure while failing to examine how resiliency in these children can help them overcome the risk factors. In a study concerning 261 Head Start children transitioning to kindergarten, Mantzicopoulos (2003) revealed that children who had been promoted to first grade were better behaved in the classroom and were more socially competent than the children who had been retained in kindergarten. The children who had been retained 
were describes as behaviorally challenged in school. It was also reported that children who had social and academic adjustment problems were more likely to be retained in kindergarten.

Fantuzzo, Bulotsky, McDermott, Mosca, and Lutz (2003) reported that Head Start teachers voiced concerns for the children in their classroom with $13 \%$ of the children exhibiting at least one social and emotional behavior problem. Eight hundred thirty-one Head Start children were observed by their teachers who then completed the Penn Interactive Peer Play Scale (PIPPS). The children were also given the Peabody Picture Vocabulary Test-III (PPVT-III) and the Expressive One-Word Picture Vocabulary TestRevised (EOWPVT-R). Children who demonstrated inattentive and hyperactive behaviors were more likely to exhibit low levels of cognitive skills. Children who were socially withdrawn had problems establishing relationships with their peers and scored lower on the PPVT-III and EOWPVT-R than their peers who had no problems establishing positive peer play relationships (Fantuzzo et al.. 2003).

Finally, Rimm-Kaufman, Pianta, and Cox (2000) reported that kindergarten teachers felt about $16 \%$ of children entered their classroom with behavior difficulties. Public school kindergarten teachers from all over the United States were recruited for this study. The researchers sent out 10,071 questionnaires, 3,995 of which were returned completed. One third of these teachers felt that half of their students entered kindergarten with difficulty following directions, working independently and in groups, communicating, and lacking essential academic skills (Rimm-Kaufman, Pianta, \& Cox, 2000). National studies approximate that $10 \%$ of children who enter kindergarten demonstrate some type of behavior problem which in turn predicts school success. Many 
of these children labeled as behavior problems are from low-income families (Thompson \& Raikes, 2007).

Social and emotional development in low income children has mainly been focused on African American students attending Head Start. The majority of research relating to early childhood development has also been conducted on Head Start students (Chang \& Burns, 2005; Coolahan, Fantuzzo, Mendez, \& McDermott, 2000; Malakoff, Underhill, \& Zigler, 1998; Mantzicopoulos, 2003; Mendez \& Fogle, 2002; SlaughterDefoe \& Rubin, 2001). Of children attending Head Start, boys showed more aggressive relationships than girls, especially the older girls of the class who engaged in the most interactive and socially competent play than the rest of their classmates (Coolahan et al., 2000). However, research related to early childhood development on children who attend other types of low-cost early childhood settings is scarce (Winsler et al., 2008). Children living in impoverished homes are more likely to suffer from troubled relationships with their families as well as other experiences that have a negative effect on the overall development (Shonkoff \& Phillips, 2000).

Stipek and Ryan (1997) found that children from economically disadvantaged families performed lower on cognitive and motivational competencies than their peers from advantaged homes. Children whose families are not poor perform better on preacademic tasks and exhibit less behavior problems than children from low-income families (Barbarin et al. 2006). Professionals and parents alike expressed that readiness must also take into account students socio-economic status as well as culture (Wesley \& Buysse, 2003). These concerns are consistent with findings from another study which revealed that of all readiness factors, socioeconomic status was the biggest significant 
predictor for differences in development among young children (Barbarin et al., 2006).

The effects of below standard neighborhoods and socioeconomic resources are the most relevant for early competence in school.

While the majority of social and emotional development in young children has focused on predominantly Black low-income children or White middle class children, few studies have focused on Hispanic children from low-income families. Hispanics are the fastest growing minority group in the United States. It is imperative that researchers evaluate the development, school readiness and academic achievement of this population. Children receiving childcare subsidies are required to participate in regular assessments in order to ensure the quality of educational services they are receiving and that they are ready to learn when they start kindergarten (Winsler et al., 2008). Children who attend these types of educational settings come from low-income families willing to work but have no form of child care. They receive government aid in order to be able to work while their children are placed in a setting in which aid is provided depending on income. The Early Learning Coalition of Miami-Dade/Monroe implemented random assessments of children in subsidized childcare. The social and emotional development of the children were assessed using the DECA.

\section{DECA}

The DECA was created by the Devereux foundation in order to evaluate resilience among preschool children (Jaeberg, Dixon, \& Weis, 2009). It was created to design a profile of children's social and emotional strengths, called protective factors. Teachers and parents complete a questionnaire which reports the frequency of children's behaviors on four subscales: attachment, initiative, self-control and behavioral concerns (Winsler et 
al. 2008). This profile is then used to reward positive behaviors while ignoring negative ones (LeBuffe \& Naglieri, 2004). The DECA has been extensively adopted in the United States by many preschool programs in order to measure the protective factors of young children. There are not many measures which adequately measure resilience in young children (LeBuffe \& Naglieri, 2004; Rosas, Chaiken, \& Case, 2007). The positive nature of the DECA allows early childhood educators to nurture the protective factors of young children as well as to help develop these skills in children who are lacking them. It does not, however, focus on the negative aspect of social and emotional development labeled as behavioral concerns on the DECA (LeBuffe \& Naglieri, 2004; Rosas, Chaiken, \& Case, 2007). For this reason, the current study only examines the three protective factors of the DECA because a multitude of research concentrating on the predictive value of behavior problems on academic success already exists.

Besides Rosas, Chaiken, and Case (2007) and Winsler et al. (2008), the protective factors (attachment, self-control and initiative) of the DECA have not been widely examined (Jaeberg, Dixon, \& Weis, 2009). While studies have replicated the value of the DECA, the extent to which individual protective factors predict long-term academic success has not, particularly in a linguistically and culturally diverse population. Attachment

Ainsworth (1991) believed that children needed a secure base from which he or she can explore the world around them. In most cases, this secure base is an attachment figure such as a mother, father or other primary caregiver. Bell and Ainsworth (1972) studied the way that mothers attend to baby's cues. It was found that baby's whose mothers responsiveness helped them attain their goal developed confidence in themselves 
to control what happens to them. Ainsworth (1992) concluded that attachment is an open-ended theory and subject to revision. Infants receive cues from caregivers on how to act in certain situations. This is the beginning of early communication and bonding between the caregiver and the infant.

The way children develop an attachment to a caregiver can be contradictory because each adult gives the child his or her own message of how the child should behave with him or her. One adult may offer more independence to the child while another may not let the child do anything for him or herself. This can confuse the child which will then make it harder for the child to develop their own sense of self. However, a child and caregiver can learn how to negotiate and accommodate to each other as they learn to communicate, allowing a child to create different "models of self" depending on which caregiver he or she is with (Bowlby, 1969). Children need to feel that they have close relationships to adults not only their parents. The effects of attachment are developed by the time children reach prekindergarten and not so important thereafter, reaffirming the importance of examining the relationship between attachment (closeness to adults) during a child's prekindergarten year and later academic achievement (Andreassen \& West, 2007).

Forming a warm, secure, and stable relationship with their mother leads to an appropriate level of attachment between mother and child. These healthy relationships allow the child to succeed later in life. Hill (2001) studied 103 African American and Euro-American kindergarten children and their mothers. Children were given the Metropolitan Readiness Test - Level 2 as well as the Sound-Letter Correspondence scale and the Quantitative Concepts Scale at the end of kindergarten to assess their pre-reading 
and pre-math skills. The Children's Report of Parenting Behavior Inventory was used to determine the type of relationship the children had with their mothers. The ParentTeacher Involvement Questionnaire was also administered to the mothers and teachers in order to determine the type of relationship that existed between the mothers and teachers.

Three main findings emerged from Hill's (2001) study of African American and Euro-American kindergarten children. First, mothers who were warm and accepting, which in turns leads to children developing secure attachments with them, were found to be positively correlated with the scores their children received in the pre-reading and premath assessments. Children whose mothers showed compassion and warmth scored better on the readiness tests than children whose mothers showed hostility. Second, the positive relationships between the mothers and teachers were positively correlated to the children's pre-reading scores. Third, the mother-child relationship influenced the child's school performance more for those from lower income families. Hence showing the importance that secure attachment with their mother can allow a child to overcome the negative effects of poverty and perform better academically.

Mothers who show warmth, sensitivity, compassion, encouragement, and support towards their children tend to develop appropriate and secure relationships with them. These relationships allow children to be confident, persistent, and affectionate (Hill, 2001; Pianta \& Harbers, 1996). These characteristics of mothers and children promote the development of a healthy attachment to each other. Pianta \& Harbers (1996) sought to find the relationship between mother-child interactions and the child's later academic achievement. Three hundred thirty-five mother-child dyads took part in two problem solving activities on the first day of the child's kindergarten year. The way the mothers 
and children behaved towards each other determined how competent their relationship was. In second, third, and fourth grade the children took the Iowa Test of Basic Skills to determine their academic achievement. Of the 335 children observed in kindergarten, 193 had second grade data, 200 had third grade data and 181 had fourth grade data. The mother-child competence factor was found to be positively and significantly correlated to academic achievement in the later grades. There was also no decline in this association from second to fourth grade which shows that secure and positive relationships in kindergarten is a consistent predictor of academic success.

A longitudinal case study of the first Head Start cohort focused on the educational goals that these former Head Start students set for themselves as opposed to their nonHead Start peers (Slaughter-Defoe \& Rubin, 2001). Ninety children ( 45 boys and 45 girls) were followed through from their first summer in Head Start to senior year in high school. Students and mothers were interviewed and academic data was obtained at three times $(1965,1973$ and 1978). By the end of the study, only 56 children were included because of relocation to other cities or the children got "lost". This study found that at Time 1, children whose mothers were more involved at home and knew their children's likes and dislikes, hence providing secure relationships with their children, were rated more favorably by preschool teachers and performed better on academic measures. It was also found that the non Head Start peers were less mature when they entered school, were more likely to give up on a task, had little drive and seemed not interested in their academic performance. At time 2, a secure mother figure in the home continued to have positive results for the Head Start students. The students who were rated more favorably in preschool and kindergarten showed more independence and initiative. As the students 
approached their final year in high school, many of the non Head Start students had dropped out of high school. Maternal encouragement continued to be a factor in the students' educational success and goal setting even though the students stated that teachers also had a big influence in their achievement.

The most important findings of this study deal with a consistent and secure relationship (mother) which then allowed the students to form other secure and close relationships with teachers that would influence their school success. It is evident that having a positive attachment to a caregiver in turn promotes closeness to other adults and therefore predicts a child's academic success. These findings reinforce the purpose of this study that early childhood education, when focused on social and emotional development, allows for better school achievement (Slaughter-Defoe \& Rubin, 2001).

The research stated above has shown that attachment is a significant predictor of later academic achievement because it allows a child to feel secure enough to explore their environment while at the same time knowing that someone is guiding them. This allows children to then be more engaged in the classroom and take more initiative in their learning as well as motivate themselves. While there are many studies that examine the way a child forms secure attachments with their mother, other research also shows that if a child was not able to form a secure maternal relationship, their relationship with their teacher will also have positive outcomes for their academic achievement (Pianta \& Stuhlman, 2004). While the DECA does have items dealing with attachment to a caregiver, most of the items in this factor focus on the closeness a child had to another adult, mainly the teacher. It is therefore imperative to review literature regarding relationships between children and teachers. 
Aber and Allen (1987) conducted a study on the effects of children who were maltreated and therefore not able to form secure relationships with their caregivers. Children between the ages of four and eight, from three types of families: 1) maltreating, 2) middle-class, and 3) receiving welfare stipends, were included in this study. The 190 children were recruited from urban and suburban communities in one New England state. Of these children, 93 were from maltreating families, 67 were from families who received welfare monies and 30 from middle class families. The children were assessed for dependency, imitation, curiosity, aspiration, cognitive maturity, interpersonal distance, attention seeking and variation when completing a task.

Two interesting discussion points resulted from the findings of this study. The first was that a factor of secure readiness emerged which composed of curiosity, variation when performing a task, high cognitive maturity and low dependency. The second factor that emerged was one of outer directedness which consisted of imitation and attention seeking. Children who had been maltreated by their families were more dependent on their teachers, scored lower on cognitive maturity and therefore scored lower on the secure readiness to learn factor. These children were not able to form secure attachments with their families and had to look elsewhere for that relationship which meant being dependent on their teacher. These children need to feel safe within their environment in order to explore the world. Maltreated children do not feel safe because of their past experiences and do not feel secure when learning in an early childhood environment. This shows that even if children cannot have a secure relationship in the home, they need to establish one with a teacher, which in turn will build their initiative to learn. 
Another study had similar results, showing that student and teacher relationships have an effect a child's academic performance, especially reading (Burchinal, PeisnerFeinberg, Pianta, \& Howes, 2002). Children who had at least two years of completed data were recruited from the Cost, Quality, and Outcomes Study (CQO) which included four states - Colorado, North Carolina, California and Connecticut. Of these children, 511 had data collected during their preschool years, kindergarten and second grade. Children were assessed on social skills by the Classroom Behavior Inventory, academic skills by the Peabody Picture Vocabulary Test-Revised (reading) and the WoodcockJohnson Tests of Achievement-Revised (math). Teachers were asked to rate their relationships with the children using the Student - Teacher Relationship Scale and parents completed several questionnaires with regard to their beliefs and practices towards childrearing.

Children who were perceived as more socially outgoing tended to perform better in their language scores when in childcare. The children whose teachers reported as having close relationships with them tended to do better on receptive language. There was a significantly higher correlation between the teacher-student relationship and language scores for the African American children than for the white children. Children who scored high on the math test were rated as more social and had parents who reported having positive child-rearing practices. All children who did well in the reading portion had teachers who reported having a close relationship with the child. This study suggests that social and emotional factors do play an important role in a child's academic success in school, especially if the child does not have a secure and positive relationship in their home environment. Teachers, especially in the preschool years need to have time to 
establish these relationships in order for their students to arrive in kindergarten ready to learn (Burchinal et al., 2002).

Other research has examined children's academic gains in prekindergarten in order to determine the effectiveness of programs and teachers. Children from eleven states who attended a state funded prekindergarten program were randomly selected to participate in a national study (Early, et al., 2007; Howes et al., 2008). The researchers investigated if specific attributes of program quality (teacher to child ratio, teacher qualifications, and program location) predicted academic and social gains of the children. Children were assessed in the fall and spring of their prekindergarten year in order to determine gains made. The findings of these studies showed that while much attention is focused on the level of education a teacher has or ratios in the classroom, children who made the most academic gains in prekindergarten experienced close and secure teacherchild relationships (Early, et al., 2007; Howes et al., 2008). Further supporting the purpose of the current study which examines how attachment as measured by the DECA predicts academic success beyond prekindergarten and into elementary school.

Similar to Burchinal et.al (2002), O'Connor and McCartney (2007) found that children who had high quality relationships with their teachers performed better on academic achievement tests in third grade. O'Connor and McCartney followed a group of 880 children from birth to third grade. The maternal-child relationship was assessed when the children were 3 years of age. The quality of the teacher-child relationships was observed four times, during the children's prekindergarten, kindergarten, first, and third grade years of school. The Woodcock Johnson Psycho-Educational Battery-Revised was 
then administered to the children in third grade in order to assess their academic achievement.

Three major finds emerged from this research. First, positive associations between the quality of teacher-child relationships and academic achievement were found. Children who had these high quality relationships with their teachers were seen being more engaged in class and attentive to the teacher, which is associated with academic achievement. Second, the high quality relationships between teacher and child seemed to buffer an insecure maternal attachment. Therefore even though a child was not able to form a secure attachment with their mother, the relationship they had with their teacher in third grade appeared to be more predictive of academic achievement than their relationship with their mother. Finally, it was observed that while teachers and children still had positive relationships in third grade, the number of these high quality relationships decreased from prekindergarten. O’Connor and McCartney (2007) suggest that this is probably due to the increase focus on instruction in third grade as well as an increase number in class size than in prekindergarten. Teachers also had to spend more time with the disruptive students and students that were more dependent on them. This study therefore reinforces the notion that fostering attachment in the early grades is key to academic success.

While most of the research dealing with Hispanic children and maternal attachment focus on the effects it has on adolescent children, there is a lack of research connecting attachment and academic success among Hispanic children, specifically during the primary years. Most of the research states that maternal attachment is a significant predictor of adolescent behavior, especially delinquent behavior and other 
behavior problems (Eamon \& Mulder, 2005; Loukas, Prelow, Suizzo, \& Allua, 2008; Loukas, Suizzo, \& Prelow, 2007; Miller, Jennings, Alvarez-Rivera, \& Lanza-Kaduce, 2009; Peacock, McClure, \& Agars, 2003). One study did mention that children of Mexican parents are academically affected by the parenting practices used by their parents. Girls reacted positively to their mothers' harsh and strict expectations while boys had negative outcomes when their fathers imposed these same harsh and strict expectations (Dumka, Gonzales, Bonds, \& Millsap, 2009). Despite the fact that there is research which ties maternal attachment and Hispanics, none show if attachment in the prekindergarten year predicts the performance of Hispanic children from low income families once in the public school system.

Two studies were found that link Hispanic children in an early childhood setting, attachment, and academic achievement, although neither contained findings similar to what was examined in the present study. One study explored how the environment of family childcare providers predicts children's pre-academic skills. It was found that the level of training and education of the providers, as well as the quality of the environment predicted a child's engagement in reading, math and science activities throughout the day (Zuniga \& Howes, 2009).

The second study investigated the effects of the relationships between young Mexican children enrolled in Head Start and their families have on behavior problems and adaptability. Fifty-five Mexican families were recruited for the study. The closeness of the Head Start child's relationship with their mother as well as with a sibling was measured. The teacher completed a checklist to assess the child's behavior problems and also completed an adaptability evaluation six months later. The close mother-child and 
sibling-child relationships were associated with less internalizing problems and positive social and emotional outcomes (Gamble \& Modry-Mandell, 2007). Unfortunately this study had no findings on how these close and secure relationships help predict the child's academic success in later school years.

What is lacking in all of the research stated above is the direct relationship that attachment has with child's academic achievement and success in school, particularly among Hispanic children from low-income families. The aforementioned research clearly points out that attachment is very important in a young child's life and without some type of secure relationship, a child's social and cognitive development may be deficient is some way.

\section{Self-control}

Bandura (1986) observed the way children cognitively control their social experiences and the way these controls influence a child's development and behavior. The conclusions he made regarding these observations became known as Social Cognitive Theory. People are active in producing and shaping the outcomes of their lives including events and experiences (Bandura, 1997, 2000). Within his social cognitive theory and belief that people are active participants in their lives, Bandura uses the term agent (Bandura, 2001). "To be an agent is to intentionally make things happen by one's actions." (Bandura, 2001, page 2).

One area of interest for was self-regulation or how a person moves from an external locus of control to an internal one. Bandura (1977) believes that if actions fall short of internal expectations they are judged negatively and those that measure up to internal expectations are judged positively. Self-regulation is the process in which a 
person controls his/her own behavior. As adults respond to children's behavior, the children develop their own standards or ideas about behaviors that are positive or negative. A person will not act on their circumstances unless they feel that they can control the outcome. They do this by controlling or regulating their behavior (Bandura, 2000). Children as early as kindergarten are able to control themselves and plan when faced with problems or complex tasks (Lin, Lawrence, \& Gorrell, 2003). It is important to understand how self-control contributes to academic success (Zimmerman \& Schunk, 1989).

During the 1960s and 1970s many studies were conducted to examine whether children at an early age are able to control their behavior in order to receive a reward for waiting. Different strategies were implemented in order to help these children delay their gratification for the reward (Bandura \& Mischel, 1965; Mischel, 1979; Mischel \& Ebbesen, 1970; Mischel \& Patterson, 1976; Patterson \& Mischel, 1975; Yates \& Mischel, 1979). Children were told that they could have a desired reward if they waited a certain amount of time or if they could not wait they would receive a less desired reward. Children in different groups looked at the real reward, a symbolic reward, or an irrelevant object. Children who viewed the real reward could not wait and chose a less desired reward rather than waiting for the reward they wanted. Children's waiting time increased when they did not have full attention on the reward (Mischel \& Ebbesen, 1970; Yates \& Mischel, 1979). Similar studies on the amount of time children could work on a lengthy task in order to receive a reward, showed that when given a plan for self-control, the children were able to work longer (Mischel \& Patterson, 1976; Patterson \& Mischel, 1975). Among those children that were given a plan, those whose plans were elaborate 
and full of details were able to work longer to receive the reward than children who had vague plans (Mischel \& Patterson, 1976).

In a follow up to his self control and delay of gratification studies, Mischel was able to locate 125 parents of the 653 children who had been assessed 10 - 12 years earlier for delay of gratification (Shoda, Mischel, \& Peake, 1990). The parents were sent a short questionnaire and 185 of the children with data were included in the follow up measure. The children who were exposed to the reward and were not given plans for control showed a correlation between their preschool delay of gratification time and self-control and their SAT scores in high school. The children who could not delay their gratification scored lower on the SAT when compared to the children who delayed their gratification when given a plan or did not have to look at the reward in question. These results suggest that self-control is important in early childhood and its role in high school achievement.

Smith and Walden (2001) examined the way 46 African American preschool aged children responded to hypothetical emotionally arousing situations. Teachers rated the children on three different scales which measured social competency, temperament, and behavioral regulation. The mothers of these children also filled out a scale which measured their reactions to their children's negative emotions. The children were assessed two separate times at school by the experimenters. During the first assessment, the children were given the Peabody Picture Vocabulary Test and the Preschool Interpersonal Problem Solving Task. In the second meeting with the experimenter, the children were given contextual and facial cue tasks to assess the children's emotional knowledge. 
Although the results from this study do not include academic outcomes, findings reveal that children who are rated as emotionally intense tend to be more aggressive and demonstrated support seeking behaviors. These children do not engage in proper selfcontrol strategies and are less socially competent. Children who avoid situations are less aggressive and have greater conflict resolution skills. Children who understand the emotionality of a situation are the children who used appropriate problem solving skills and were able to control their behaviors and emotions. Social competence is associated with the way children control their behaviors and those students who were better selfregulators showed higher vocabulary skills as assessed by the Peabody Picture Vocabulary Test (Smith \& Walden, 2001). Other research shows that early vocabulary is a predictor for later academic success (Agostin \& Bain, 1997; Fantuzzo, Bulotsky, McDermott, Mosca, \& Lutz, 2003; Kurdek \& Sinclair, 2001; Mendez \& Fogle, 2002). The major problem with this study is that it only consisted of a small group of African American children and therefore the results are not transferable to other groups of children. The research also did not examine how self-control effects academic achievement which is the main purpose of the present study. Another study examined the effects preschool social behavior has on first grade academic success for 291 French Canadian children from Montreal, Canada (Normandeau \& Guay, 1998). The kindergarten teachers of these children completed the Preschool Social Behavior Questionnaire, which is a 3 point scale that measures aggression, anxious-withdrawn behavior, and prosocial behavior. The children were also administered the Test of Nonverbal Intelligence and the Peabody Picture Vocabulary Test - Revised in kindergarten. At the beginning of first grade, the first grade teacher 
completed the Cognitive Self-Control Scale and academic achievement was measured using math and French school grades at the end of the year.

Several associations were made using a structural equation model. The first important finding was that the children's social behavior in kindergarten was positively related to their cognitive self-control in first grade. This in turn was positively related to their school achievement at the end of first grade (Normandeau \& Guay, 1998). This study, although with a very different population than the current study, demonstrates the relationship between a child's social behavior and their academic success later in school. The children who were aggressive and could not control their behavior in kindergarten were the same children who did not demonstrate self-control with school tasks in first grade and performed poorly in their academic grades at the end of the year. These results support the hypothesis that social and emotional development can predict academic success beyond kindergarten.

Agostin and Bain (1997) followed 184 children from three elementary schools in a large southeastern community from kindergarten into first grade. The majority of the students were African American children at risk for school failure. Teachers were asked to fill out the Social Skills Rating System (SSRS) at the end of kindergarten and a year later the students were assessed in Reading and Math using the Stanford Achievement Test-8 (SAT-8) at the end of first grade. The self-control subscale of the SSRS accounted for $35 \%$ of the variance in the SAT- 8 math and reading scores at the end of first grade. Along with language and cooperation, self-control was found to be one of the most important variables in predicting academic achievement in first grade. Self-control was also found to predict whether children will be promoted, retained, or kept in intensive 
classes at the end of kindergarten and first grade. These results uphold the hypothesis that self-control is a predictor for academic success in third grade.

Learning related social skills are those skills such as listening, following directions, participating, staying on task and organization. These skills fall into the categories of social competencies such as independence, cooperation, responsibility and, most importantly for this study, self-control. Learning related social skills are similar to learning skills that school age children exhibit. The relationship between learning related social skills and academic success was studied over a one year period among 72 predominantly white preschool children with well-educated parents living in the Chicago area (McClelland \& Morrison, 2003). Three children were excluded from the sample because English was not their first language. Teachers completed the Social Skills Rating System and the Child Behavior Rating Scale at Time 1 (3 and 4 years old) and Time 2 (4 and 5 years old).

McClelland and Morrison (2003) found that learning related social skills are present in children as early as three years of age and the skills remained stable over a one year period. The children in this study showed learning related social skills based on their measures of assertion, self-control and cooperation as well as mastery behaviors which include planning, organization, and completing tasks. There was no significant difference between the two times these skills were measured, which leads one to conclude that learning related social skills do not change over time. However, these results cannot be generalized to other populations because only the learning related social skills of predominantly white children with well-educated parents were studied. Other cultures, specifically Hispanics may show different results and those children were 
purposefully excluded from the study. This study did not investigate the predictive value that learning related social skills have on academic achievement.

In a study examining the self-control of 204 Hispanic high school students, Miller, Jennings, Alvarez-Rivera, and Lanza-Kaduce (2009) found that effective parenting and maternal attachment was correlated with high self-control among Hispanic adolescents, which in turn led to less defiant behaviors. However, those students who had unhealthy attachments to their mothers demonstrated less self control and were more deviant resulting in criminal activity. Unfortunately this is the only study that has focused on a homogeneous sample of Hispanic children, although the age group is very different from the current sample. It is necessary to examine how Hispanics self-control, specifically during their prekindergarten year predicts their school success. There is no evidence in the literature that this topic has been or is currently a focus of recent research studies.

The majority of studies found regarding self-control in preschool aged children only showed how it predicts later behavior or social competence and were mainly conducted on Anglo or African American children (Coolahan, Mendez, Fantuzzo, \& McDermott; Fantuzzo, et al. 2003; Fantuzzo \& McWayne, 2002; Ladd, Kochenderfer, \& Coleman, 1996; Lindsey, 2002; Mendez \& Fogle, 2002). There is little research which includes Hispanics as part of the population. Research in which self-control exhibited by four-year olds to predict academic success is scarce.

\section{Initiative}

Erik Erikson was not in agreement with many of Freud's views of human development such as the idea that a person's personality is developed in the first five 
years of life or that a person develops his/her personality based on five psychosexual stages. Erikson believed that human behavior is in fact driven by a person's desire to associate with others and therefore felt that a person goes through psychosocial stages throughout their whole life (Santrock, 2004). He thought that people developed their personalities throughout eight stages within their life. The third stage in particular, initiative versus guilt, brings into light the social and emotional factor of initiative. It is during the preschool years that a child is faced with more challenges than ever before. Children are expected to become responsible for themselves as well as their actions. Children at this age enjoy exploring the world around them and leading activities. It is the parents' job to allow them this freedom in order for the child to develop a purpose for their actions. If the parent does not allow a child to develop an initiative to explore their environment, children will end up with a feeling of guilt or having no purpose for their actions (Erikson, 1950). It is through this psychosocial stage of development that children begin to have motivation for their actions which in turn drives their initiative.

As with self-control, children at first are motivated by external forces such as prizes. As children become aware that their actions make them feel good about themselves, the motivation becomes internal which allows their initiative to increase. Children's satisfactions become generated by the feelings the outcomes produce not by the prizes given by parents or teachers. This internal motivation fosters initiative, which then allows the child to develop their own internal initiative for behavior (Amabile \& Hennesey, 1992; Ford, 1992). External motivators hinder initiative so they must be removed slowly from a child's reward system. 
Initiative includes a broad range of features such as setting goals and aspirations, making plans, keeping commitments, as well as having effort, perseverance, and resilience (Santrock, 2004; Ford, 1992). Initiative is critical in a student's achievement because a child needs to set goals, plan how they will reach these goals and monitor their progress (Bandura, 1989). Children with high initiative have an outlook on life that they can accomplish their goals while those with low initiative feel helpless and therefore do not set challenging goals for themselves because they feel they cannot reach them. These children lack motivation and are only concerned with the outcome as opposed to the process of reaching the outcome. Children with high initiative and motivation, tend to self-talk in order to pay attention and think about strategies that they have used before (Ford, 1996).

Agostin and Bain's (1997) study not only looked at self-control but also features that are related to initiative. Children who demonstrated high assertion and cooperation scores also scored well on the math and reading portions of the SAT-8. Assertiveness and cooperation are one of the many categories that fall under the subscale of initiative. Children who are assertive tend to show qualities of initiative such as organizing games with others, having different problem solving strategies and persistence. This study shows how social and emotional development, specifically initiative, displayed in kindergarten predicts school success in first grade. Children who have not matured to the point where they can internalize their behavior fall behind their peers academically. However, what is not known is how social and emotional development predicts academic success beyond first grade. 
Malakoff, Underhill, and Zigler (1998) recruited 78 preschoolers for a study involving levels of initiative. Of these, 26 were African American children that attended an inner city Head Start program, 26 were African American inner city children with no preschool history and 26 were white middle-class children who attended a private preschool. The children were given four measures of initiative which included curiosity, preferences for challenging tasks, persistence on challenging tasks and preferences of reinforcement. Curiosity was measured by offering the children a choice to view a picture they have never seen or a known picture. Preferences for challenging tasks was measured by giving children the option of completing a puzzle with either two-thirds of the pieces already glued, one-third of the pieces already glued or none of the pieces already glued. Each puzzle was the same. Children were asked to play a game of Labyrinth in which they had to get a marble from one side of the board to the other and back without touching the marble with their fingers. The amount of times children asked for help or tried to push the marble with their fingers was used to measure their persistence. Finally, at the end of the session, the children were allowed to choose which type of reinforcement or prize they wanted for completing the tasks. They could choose between an intrinsic reward (a certificate) or an extrinsic reward (party favor or cookies).

The results demonstrate that middle class children in a private preschool were more likely to select the novel picture, therefore proving to be more curious. These children barely asked for help while trying to complete the labyrinth, while the inner city children with no school experience asked for help the most. Head Start children most often selected the most difficult puzzle, requested less help than the children with no school experience and chose the intrinsic reward more than the two other groups. Head 
Start children show more attributes of initiative than children with no school experience or middle class children in a private school. These findings illustrate the importance of an early childhood setting for children from disadvantaged backgrounds, however what is not known is how these children will perform once they get to a public elementary school. The limitation of this study to African American and white middle class children suggests that more research needs to be completed regarding Hispanic children from low income families.

A longitudinal case study of the first Head Start cohort which focused on the educational goals that these former Head Start students set for themselves as opposed to their non-Head Start peers studied not only the attachment they had to their mothers but also the initiative they had to carry out these goals (Slaughter-Defoe \& Rubin, 2001). The results regarding initiative showed that students who had attended Head Start viewed themselves as more academically motivated than their non Head Start peers. As the students got older, they moved from fulfilling their mothers' expectations to fulfilling the goals they set for themselves, therefore moving towards an intrinsic motivation or high initiative as opposed to an external motivational factor. It was also found that the students' early school grades were predictors of their later grades and goal attainment. Limitations to this study include a lack of Hispanic children in the sample as well as a clear relationship between initiative as a predictor of academic success.

Motivation as a synonym for initiative has become very common as researchers continue to investigate the relationship between social and emotional development in early childhood and academic success. African American children continue to be a heavily studied group. A publically funded preschool for at risk children was used as the 
setting in order to study the initiative of 169 four year old African American children (Turner \& Johnson, 2003). The children's initiative was measured by the parents at the beginning of the year and by their teachers in the middle of the year. The parents and teachers rated the children on three items: preference for a challenging task, persistence and positive affect in response to learning. The children's academic success was measured at the beginning and end of the year by the Kaufman Survey of Early Academic and Language Skills (K-SEALS) evaluation. The purpose of the study was to identify factors that may help predict academic gains that students will make in the future.

Turner and Johnson (2003) took into account the child's prior achievement by controlling for the K-SEALS assessment the children took at the beginning of the year. While the results showed a small yet significant prediction (5\% of the variance), controlling for prior achievement allows the true measure of initiative as a predictor of academic success to be seen. Without controlling for prior achievement, motivation accounted for $12 \%$ of the variance in academic achievement (Turner \& Johnson, 2003). The results of this study may seem small and insignificant, but after accounting for previous academic achievement, the fact that initiative still plays a role in academic success is great. Two limitations to this study include children's academic scores from only one year were used as the independent variable and the sample consisted of only African American children.

While there is a lack of studies involving the social and emotional development of Hispanic children and their academic success, few studies have shown that initiative predicts a child's academic performance in math and reading. Black and Hispanic 
children were followed from kindergarten to first grade in order to determine the influences of cognitive and social factors on first grade math and reading outcomes as well as first grade social maturity (Reynolds, 1989). While the population of this study consisted of predominantly Black children $(1,470)$, there was a small portion of the population that consisted of Hispanics (69). The children were assessed upon entering kindergarten using the Iowa Test of Basic Skills (ITBS) in order to determine their cognitive readiness for kindergarten. At the end of kindergarten, they were again assessed using the ITBS in order to measure their reading and math achievement. The children's level of motivation was also measured in the spring of kindergarten through a teacher observational questionnaire. Initiative is compromised of various components, one of which is motivation and the other persistence, both of which were measured by the teachers' observations. At the end of first grade the students again took the ITBS and their first grade teachers filled out another Likert type questionnaire which measured their social maturity.

The results suggest that initiative does indeed predict the academic success of first graders, especially in math. While initiative predicted both reading and math outcomes, it accounted for a greater proportion of variance on first grade math outcomes and social maturity in first grade (Reynolds, 1989). These results support the hypothesis that initiative is a predictor of academic success among children with low socioeconomic backgrounds.

Another study involving 666 White and Hispanic children from west and south Texas also examined the predictive value of cognition, motivation and emotion on academic success (Stevens, Olivarez, Jr., \& Hamman, 2006). Stevens, et al., examined 
the cultural gap that exists between Hispanic and white children in math achievement. Children between fourth and tenth grade were included in this study with almost $60 \%$ of the students enrolled in eighth grade. The students completed the Cattell Culture Fair Test in order to measure their general mental ability. They also completed the calculation and math fluency portion of the Woodcock Johnson III Test of achievement in order to measure math achievement. They also completed a mathematics interest inventory, a self-efficacy math experiences scale and problem solving scale, as well as an academic self-regulation questionnaire in order to measure motivation. The students were also asked to describe their prior math achievement in previous grades by stating the types of grades received in report cards on previous years.

Hispanic children were at a disadvantage in mathematics achievement when compared to white children. Stevens, et al., (2006) found that although the Hispanic children in the study had more motivation and self-efficacy, they did not perform as well in math achievement tests than their white counterparts. Math self-efficacy was the strongest predictor of math performance, even though it was not considered a strong variable. The most interesting finding was that emotional feedback that the students received explained more of the variance in math achievement than the students' general mental ability. While this model for finding the influences on mathematics achievement was a good fit for the white children it was not for the Hispanic children and therefore cannot be used to generalize results for Hispanic children. While this study does show that initiative predicts mathematics achievement, the children are older and it is not predicting the academic achievement from social and emotional measures assessed before starting school. 
Children with high initiative demonstrate positive learning related behaviors as well as academic achievement in later schooling (Stipek, 1993). Two hundred sixty-two prekindergarten and kindergarten children from private and public schools were included in a study to find a relationship between initiative and academic success (Stipek \& Ryan, 1997). Half the population (47\%) were Latino, with 82 of these children speaking Spanish as their primary language. Children were followed for two years into kindergarten and first grade. The children were interviewed during the fall of the first year of the study to measure the way they perceived their aptitude as well as their attitude towards school. The children were also asked about their attitudes towards school and anxiety about performance in school. Academically, children were assessed using the Woodcock-Johnson Achievement Test and the Peabody Individual Achievement Test during the fall and spring of the first and second year of the study. The researchers in this study compared children from higher income families (advantaged) with children from lower income families (disadvantaged).

Children from disadvantaged families tended to select more challenging tasks after succeeding than the advantaged children. Their enjoyment increased and anxiety decreased from the beginning of the year to the end of the year, while the reverse was true with children from advantaged families. In preschool, the disadvantaged children showed more effort while the advantaged children showed more effort in kindergarten (Stipek \& Ryan, 1997).

The initiative measures that were assessed in the fall predicted the academic measures in the spring. Children who worried more, were more dependent and anxious made less academic gains than the children who chose difficult tasks and showed 
enjoyment in school for both groups. This study shows that children typically rate their skills very high at the beginning of school and as the year progresses, their expectations for success and achievement decreases. Children also enter school with self-confidence and ready to take on challenging tasks yet towards the end of the year, children choose less challenging tasks and worry more even if they have high expectations (Stipek \& Ryan, 1997). The cause of this decrease in motivation and initiative is unknown but may be caused by the lack of social and emotional skills taught in the early years and the emphasis on academic tasks that children may not be ready to learn.

While the research stated above shows how initiative can be correlated to how students feel about school, themselves, and their academic performance, it is lacking the direct relationship initiative has on a child's academic achievement and success in school, particularly among Hispanic children from low-income families. The research stated above clearly points out that children need to have a high degree of initiative in order to succeed in school. Therefore this study will examine if initiative predicts academic success among Hispanic children from low income families.

\section{The Current Study}

Attachment, initiative and self-control are very important within the spectrum of social and emotional development, and this study specifically examined if they predict academic achievement from kindergarten through third grade. Social and emotional development is an extremely large and complicated psychological domain to be studied in its entirety. Teachers and parents have cited many different social and emotional skills that are important for children to have in order to start school ready to learn. 
It is evident from all the research presented that the development of social skills during the preschool years appears to be very important for children's school readiness and academic success. However, most of the research done on social and emotional development has been conducted on either predominantly middle class Anglo children or low income African American children. The lack of data on Hispanic families is a big omission in a country in which Hispanics are the fastest growing and largest minority group. The cultural differences that may arise may significantly affect the home and school connection. They may also affect the children's learning approaches and styles when it comes to school tasks and assessment. The research relating to attachment, self control and initiative cited above lacks information regarding young children from low income Hispanic families.

The present study attempted to determine if social and emotional development predicted academic success from kindergarten to grade 3 . It is a secondary data analysis from the Miami-Dade School Readiness Project, which collected data on economically disadvantaged preschoolers in Miami, Florida (see Winsler et al., 2008, for a complete description). This university and community evaluation and research project examined the effects of childcare on school readiness of children receiving subsidies (Winser et. al., 2008). It is important to study if social and emotional development predicts academic achievement among Hispanic children because research is limited, even though there is extensive literature on how it affects African American and White children. The goal of the current study was to preliminarily answer questions about Hispanic children and their social and emotional development as they enter school and whether these protective factors significantly predict academic achievement in the later years. 


\section{CHAPTER III}

\section{METHODS}

This purpose of this study was to explore the relationship between the social and emotional development of prekindergarten children and their academic success from kindergarten to grade three. Specifically, it was undertaken to determine if a relationship existed between the three DECA protective factors (initiative, attachment and selfcontrol) and children's outcomes on the Stanford Achievement Test, Tenth Edition, the Florida Comprehensive Assessment Test and their academic grades in reading and mathematics. This chapter includes a description of the sample, instruments, procedure and data analysis.

\section{Participants}

The participants of this study were a subgroup of children from a larger university assessment intervention program that has followed over 3,000 children from their prekindergarten year until the present year, 2010 .

\section{Population}

Miami-Dade County is a racially, ethnically, and economically diverse community. According the U.S. Census Bureau, in 2007 the population of Miami Dade County consisted of 62\% Hispanic/Latino, 19.8\% Black/African American, and 21\% Caucasian/other people, while the United States consisted of 15.1\% Hispanic/Latino, 12.8\% Black/African American, and 73.2\% Caucasian/other people (U.S. Census Bureau, 2009). The U.S Census Bureau also reported $15.3 \%$ of people reported living below poverty in Miami-Dade County (U.S. Census Bureau, 2009). Miami-Dade also has a large proportion of children under the age of 18 living in poverty (22.9\%). English, 
Spanish, and Haitian Creole are supported languages within the community with $67.9 \%$ of the population speaking a language other than English in the home (U.S. Census Bureau, 2009).

Miami-Dade County Public Schools is currently the fourth largest school district in the country serving approximately 80,000 children. Of those 80,000 children, those who were turning 4 years old before September 1, 2003 and entering some type of prekindergarten setting (public, private, center-based, or family daycare) were included in a large university, community and multi-agency collaboration project whose goal was to evaluate the curriculum and programs of non Head Start childcare services. The Assessment Intervention Program assessed the cognitive and social emotional development of these 4-year-olds and has continued to follow them to the present year, 2010.

Subsidized childcare. The Subsidized Childcare Program is one of the many instituted by Florida's Temporary Assistance for Needy Families (TANF) Program. The purpose of the TANF program is to help low income families decrease their dependency on the government, promote job preparation and work, as well as allow children to be cared for while the parents work. Children who receive subsidized childcare are those children under the age of 12 whose families live below the poverty line. Depending on the parents' income, families pay for childcare on a sliding scale (Florida Department of Children \& Families, 2009). These programs are designed to allow low income families access to high quality childcare that they would normally not be able to afford. Parents can use the subsidies to choose from licensed childcare providers as well as unregistered ones. Of the children whose parents receive subsidized childcare, $4 \%$ are in a group 
home care, $8 \%$ are taken care of in the home, $29 \%$ attend a family day care and $59 \%$ attend a childcare center (Winsler et al., 2008).

The majority of research relating to early childhood development is conducted on Head Start students (Chang \& Burns, 2005; Coolahan, Fantuzzo, Mendez, \& McDermott, 2000; Malakoff, Underhill, \& Zigler, 1998; Mantzicopoulos, 2003; Mendez \& Fogle, 2002; Slaughter-Defoe \& Rubin, 2001). However, research related to early childhood development of children who attend subsidized childcare is scarce. According to Winsler et al. (2008), there is very little research on the effects of subsidized childcare on the children who receive these services. While many children are eligible for subsidized childcare, only $12-15 \%$ of children actually receive the services. Many children may be lacking the important skills for social and emotional development because their parents are not taking advantage of subsidized childcare.

Hispanic. The Hispanic population is the largest minority population in the United States (15.1\%) and makes up 62\% of the population of Miami-Dade County (U.S. Census Bureau, 2009). The Hispanic community is compromised of people of various cultures and people from many countries who have immigrated to Miami-Dade County and their descendents. Hispanic families have been immigrating to Miami-Dade County since the 1960s when they came as a result of the Cuban revolution (Zuniga, 1998). Since then many from other countries such as Argentina, Uruguay, Nicaragua, Guatemala, Honduras, Peru, Mexico, Colombia and Venezuela have also arrived (Zuniga, 1998).

While the Hispanic culture is comprised of people from many different countries who consider themselves different from each other, they do have similar traits that are 
typically found among the all the different Hispanic groups. As a whole, the Hispanic culture is considered a high-context culture (Hall, 1976; Kaiser \& Raminsky, 2003; Zuniga, 1998; \& Lynch, 1998). High-context cultures, according to Hall (1976), value interdependence as opposed to individuality. The family is looked at as a whole and you belong to your family. Hispanic families put the parent-child relationship before all others, creating pre-school children who are very dependent on their parents. Many of these children sleep in their parents' bed, are still spoon fed, cannot pick up after themselves, tie their shoes, or perform any other behavior deemed independent (Lynch 1998; Zuniga, 1998). A well-educated child in the Hispanic culture is considered one who is knowledgeable in human relationships and has the skills to have good and proper relationships with family members. Children must be well-mannered and have respect for authority in order to be considered well-educated (Zuniga, 1998). Given that Hispanics rely so heavily on non-verbal communication, large gestures and hand movements are used when speaking. They also tend to have a closer proximity when speaking to someone (Lynch, 1998; Zuniga, 1998). Physical contact is also very important among high-context cultures, thus making Hispanics very prone to hugging as well as carrying and holding babies when they would be considered too big to carry in other ethnic groups. They tend to prefer to work in groups and use humor as a stress reliever (Kaiser \& Raminsky, 2003).

While to a Hispanic child these behaviors are normal, in a school setting in the United States, non Hispanic teachers and students consider some of these behaviors disruptive. Children who are raised to remain dependent on their parents as long as possible are typically seen by U.S. teachers as burdens who take time away from other 
children. There are children who enter kindergarten who do not know how to feed themselves, throw away a piece of paper or clean themselves after going to the bathroom (Lynch 1998; Zuniga, 1998). The humor and large gestures that Hispanic children use are seen as outbursts in the class and teachers may label the students as behavior problems (Kaiser \& Raminsky, 2003). Because Hispanic adults prefer to work in groups, so do their children, which makes it a problem for teachers in many U.S. schools who require students to spend a large amount of time completing independent seat work. The children may begin to talk to each other in order to make this work more pleasurable (Kaiser \& Raminsky, 2003). Since they make up largest minority group in the United States and the largest ethnic group in Miami-Dade County, it is of great importance that research is conducted to understand how the social and emotional development of Hispanic children preditcs their academic success.

\section{Sample}

The present study investigates academic achievement over time made by urban Hispanic children in poverty receiving subsidized childcare services beginning in the 2003-2004 school year, their pre-kindergarten year, through third grade (2007-2008). The participants represent a subgroup of one cohort of children included in the Assessment Intervention Program. Hispanic children from low-income families who qualify for and receive childcare subsidies to attend regular, center-based childcare programs in the community were studied $(N=1,978)$. This subgroup includes all the Hispanic children whose parents received childcare subsidies during the 2003-2004 school year and whose teachers had completed the teacher version of the Devereux Early Childhood Assessment (DECA). 


\section{Instruments}

The instruments described below are the assessments currently used by MiamiDade County Public Schools in order to track the progress of students and evaluate the effectiveness of the Voluntary Pre-kindergarten (VPK) program. These are not all of the assessments used by the county but deemed the most appropriate in order to answer the research questions of this study.

Devereux Early Childhood Assessment (DECA).

The students in this study were assessed during the fall of their prekindergarten year (2003) using the Devereux Early Childhood Assessment (DECA). The DECA is a social and emotional assessment that uses teachers' and parents' reports on students' behavior between the ages of two and five. It took 2 years to develop and nationally standardize. The DECA is a checklist in the form of a 5-point scale of 37 observed behaviors divided into the following factors: initiative, self-control, attachment, and behavioral concerns (LeBuffe \& Naglieri, 2009). The initiative items of the DECA includes questions such as: choosing a challenging task, doing things for themselves, being persistent, playing make-believe, trying new activities, finding different ways of solving problems, organizing and asking other children to play, making decisions, concentrating on tasks and saying positive things about their future. The attachment factor of the DECA is measured by items that observe behaviors such as: showing affection to adults, asking adults to play or read, seeking help from others, showing an interest in what others are doing, trusting familiar adults, acting happy when their parent returns, showing affection towards familiar adults, and responding positively when an adults comforts them. Self-control is measured by behaviors dealing with handling 
frustration, listening and respecting others, managing anger, showing patience, cooperating, sharing, controlling anger, and accepting another choice when their first option was not available (LeBuffe \& Naglieri, 2009).

For the purpose of this study, only the teachers' reports of student behavior in the three protective factors were used, excluding the behavioral concerns factor. This factor was not included in the study because this study only focused on the positive aspect of social and emotional development and its relationship with academic success. The behavioral concerns factors were also excluded because the DECA promotes resiliency and how to teach children positive skills needed as opposed to focusing on negative behaviors (LeBuffe \& Shapiro, 2004). Following the first 4 weeks of school, the prekindergarten teachers completed the DECA checklist for each student in their class.

The scores of tests that measure something consistently are said to be reliable (Tashakkori \& Teddlie, 1998). The internal reliability, as reported in the Technical Manual, for the three DECA factors used in this study are as follows: initiative $=.90$, selfcontrol $=.90$, attachment $=.85$ (LeBuffe $\&$ Naglieri, 1998). The test-retest reliability was measured over a 24 hour period. The test-retest reliability for teachers' rating (.87-.94) was much higher than for the parents' rating (.55-.80), therefore further supporting the decision to only include the teachers' ratings in this study (LeBuffe \& Naglieri, 2009).

The validity of a test refers to the whether the test measures what it is supposed to measure (Tashakkori \& Teddlie, 1998). The criterion-related validity, found in the Technical Manual, of the four DECA factors ranged from .71 to .85 (LeBuffe \& Naglieri, 1998). The DECA was able to classify $69 \%$ of children who demonstrated behavioral concerns in association with another assessment of behavior, the Devereux Scales of 
Mental Disorders (Naglieri, LeBuffe, \& Pfeiffer, 1994). The construct validity was determined by correlating the total protective factors with the behavioral concerns and were found to be inversely correlated at -.65 , which suggests that if a child has high protective factors they will not have behavioral concerns and vice versa (LeBuffe \& Naglieri, 2009).

\section{Stanford Achievement Test, Tenth Edition (SAT-10).}

The SAT-10 is a norm referenced test that measures reading and mathematical achievement. It is an untimed test and the students work on the test until it is completed. The SAT-10 consists of a full length test and an abbreviated version as well as other versions of the test that cover kindergarten through $12^{\text {th }}$ grade. It was standardized in 2002 and the population reflected the K-12 national population. Over 350,000 students participated in the standardization of this new SAT test. Scores reported include raw scores, scale scores, percentiles and grade equivalents (Carney, 2004; Morse, 2004). During the month of March of their second grade year (2007), the students in the sample took the SAT-10.

The test-retest reliability of the SAT-10 reported from repeated testing of students fell between the mid $.80 \mathrm{~s}$ to mid $.90 \mathrm{~s}$ for the full length test and in the $.80 \mathrm{~s}$ for the abbreviated version. Another reliability measure correlated the different versions of the test and found the equivalent forms reliability fell in the .80 s for most of the test forms (Carney, 2004). The reliability coefficient, for equivalent forms of the test, of the reading and mathematics is .88 , which supports the use of these two versions for this study (Harcourt Brace, 2003). 
The SAT-10 was compared to a number of other tests that also assessed a child's academic achievement as compared to other children in order to provide validity that it actually measured a child's academic ability. The correlation between the SAT-10 and the SAT-9 runs between .70 and .80 (Carney, 2004).

The Florida Comprehensive Assessment Test (FCAT).

The FCAT is administered every March to students in grades 3 through 10. It has been administered annually since 1998. The FCAT measures learning by students along the Sunshine State Standards (SSS) in reading and mathematics. Other scores from the FCAT include a writing and a science section, which were not used in this study. In third grade, the students receive scale scores ranging from 100-500, which are then converted to five levels and developmental scores ranging from, 0-3000. A student can receive a level 1 (the lowest) through level 5 (the highest). In third grade, students must score at least a level 2 in order to pass to fourth grade (FDOE, 2007). The students in this study took the FCAT in March of 2008 and the scale scores were used for the data analysis portion of this study.

The FCAT measures the knowledge that students have of the Sunshine State Standards (SSS), the Florida statewide curriculum. The degree to which the FCAT is reliable means that it consistently measures students' knowledge of specific concepts of information (Tashakkori \& Teddlie, 1998). The internal consistency reliability, using Cronbach's Alpha, of the 2006 FCAT for the reading portion is .89 and .90 for the mathematics. The item response theory marginal reliability, which tests the standard error of measurement, was reported as .92 for reading and .90 for mathematics in the 
2006 assessment (FDOE, 2007). These numbers provide support that the results of the FCAT provide consistent scores for reading and mathematics.

If an assessment is said to be valid, it refers to the fact that the test measures what it is supposed to measure (Tashakkori \& Teddlie, 1998). Therefore the FCAT is supposed to measure the knowledge a student has of the SSS. When an assessment is compared to another, a value for its concurrent validity is reported (Tashakkori \& Teddlie, 1998). The validity of the FCAT when compared to the SAT-9 was .84 in reading and mathematics (FDOE, 2007), suggesting that the FCAT and the SAT-9 measure similar concepts for reading and mathematics.

The FCAT also has a portion that is norm-referenced and compares the children from the state of Florida with children from other parts of the country. This portion of the test is called the Norm Referenced Test (NRT). The internal consistency reliability of the third grade reading and mathematics NRT portion was reported as 0.92 . The correlation between the FCAT and NRT for reading and mathematics was reported as 0.84 providing evidence of concurrent validity (FDOE, 2007).

Academic Grades

The students' grades at the end of each academic year from kindergarten to third grade were also used to assess their academic success. Grades are given based on criterion referenced tests given by the teacher in class of objectives taught throughout the week, coinciding with the instructional pacing guide of Miami-Dade County Public Schools. Students received grades in mathematics, science, social studies, language arts, reading, and writing, as well as conduct and effort. For the purpose of this study, only 
the mathematics and reading grades were used since the FCAT and SAT provide scores in only these two academic areas.

In kindergarten, students received grades of $\mathrm{E}$ (excellent), $\mathrm{S}$ (satisfactory), or $\mathrm{N}$ (needs improvement). Typically, teachers used the grading rubric of older elementary grades average $(90 \%-100 \%=\mathrm{E}, 70 \%-89 \%=\mathrm{S}, 69 \%$ and below $=\mathrm{N})$. These grades can be converted to a point system that is used in the upper grades as well $(E=4, S=2, N=O)$. The teachers in grades 1 through 3 use the conventional A-F letter grades that were then converted into a point system of $0-4$. These teachers used the grading rubric as follows $90 \%-100 \%=\mathrm{A}(4), 80 \%-89 \%=\mathrm{B}(3), 70 \%-79 \%=\mathrm{C}(2), 60 \%-69 \%=\mathrm{D}(1)$, and $59 \%$ and below $=\mathrm{F}(0)$.

Academic grades consist of tests students take in class as well as feedback that is given to them by their teachers. These grades are also reflective of any differentiated instruction that has taken place in the class in order to help students achieve academically. They show how a student performs over time and are not a single chance score (Marsh \& Yeung, 1997). By including students' academic grades and not just standardized test scores, the ecological aspect of learning is also included. Children are affected by the environment around them. The relationships between the people directly and indirectly in their lives can affect their performance in school as well as their behavior in general (Bronfenbrenner, 1979). In the 1990s, 65\% of local school districts had a grading policy and the grades were based on a percentage cutoff (Polloway et al., 1994).

Teacher given grades have been under scrutiny for many years. Teachers as well as parents have been confused about how to give students grades on their report cards 
even if the school district they work in has guidelines to follow (Brookhart, 1993; Bursuck et al, 1996; Randall \& Engelhard, 2009a). Research has found that elementary school teachers tend to give higher grades than middle school teachers (Randall \& Engelhard, 2009a). Teachers in elementary, middle and high schools primarily give grades based on achievement although some teachers do take into account behavior and effort and may raise or lower a grade based on these factors (Randall \& Engelhard, 2009b). Other teachers believe that students' grades should be based on the growth they make during a marking period as well as their individual abilities (Tomlinson, 2001). The problem with this view is that two children may receive the same grade but one is not working on grade level and the other is.

Student grades should provide a direct measure of successful performance and an indirect measure of effort (Bursuck et al., 1996). The harder a child tries the better grades they get. The question remains whether the same grading standards should be used for every student regardless of ability. There are teachers who feel grades are payment for work requirements; some believe that grades should be given from a calculated score; while others think that grades reflect academic ability. Many teachers believe that grades should be the result of improvement and ability (Brookhart, 1993; Bursuck et al., 1996).

Teachers, at times, base grades on consequences the students may receive at school or home. For example, a teacher may give a better grade to a student because he/she does not want to deal with an angry parent or in order to allow the student to participate in an extracurricular activity (Brookhart, 1993). Other teachers pass students if they make an effort regardless whether the student is receiving a passing grade in the 
class. Teachers mainly assign grades based on in-class work and homework as well as tests, quizzes and projects (Bursuck et al., 1996).

There are no exact reliability or validity coefficients to give an exact view regarding the consistency on how teachers assign student grades. However, the public school system uses academic grades in order to track achievement and success throughout a child's academic career and therefore end of the year academic grades were included in this study. We can only account for what teachers say they use as a rubric, even though the majority of school districts have strict grading policies in which teachers may only use percentage scores to assign grades because the students receive separate effort and conduct grades, as in Miami-Dade County Public Schools (Pollaway et al., 1994).

\section{Research Design}

An ex-post facto research design was appropriate for the current research study because of the attempt to find relationships between social and emotional development and academic achievement. The researcher explored these relationships from Grade 3 back until kindergarten in order to determine when the relationship began between the independent and dependent variables as well as to determine when the relationship was the strongest. An ex-post facto design is used in naturally occurring experiments when the independent variable is not manipulated (Leedy \& Ormrod, 2005). This study used data that have been used and are currently used in Miami-Dade County Public Schools which categorizes this research as a natural experiment.

In order to control for Type I error rates, the researcher used the Bonferroni approach across all the regressions using the formula $p<\alpha / n-1$ in order to determine 
significance and $p>\alpha / \mathrm{n}-1$ to determine those factors which were not significant (Tabachnick \& Fidell, 2001).

\section{Procedures}

Archived data were examined in order to study Hispanic children's academic success from kindergarten through third grade as predicted by their pre-kindergarten social and emotional development. Permission was obtained to access the database to obtain pre-kindergarten DECA assessments as well as to the students' kindergarten through Grade 3 academic grades, SAT-10 and FCAT results. The data did not contain specific child identifying information. A specific child ID number had already been assigned. The students' pre-kindergarten scores on the DECA, as assigned by their prekindergarten teacher, were analyzed to determine what relationships existed between the students' pre-kindergarten social and emotional development and their academic success, as determined by school grades, SAT-10 and FCAT scores.

\section{Collection of Data}

The data for the present study were collected by individuals other than the researcher. Since it was part of a larger study, information that has been stored in a database was used. Graduate students from a major university collected all the DECA questionnaires and entered the scores from the teacher observations. The public school system provided the university with the students' academic grades and scores on the SAT-10 and FCAT. 


\section{Data Analysis}

This study used a series of multiple regressions to determine the relationship between the DECA social and emotional factors at the beginning of pre-kindergarten and academic success from kindergarten through grade three.

Several hierarchical regressions were performed between the three DECA factors, measured in preschool, as the predictor variables and academic grades, FCAT and SAT scores as the criterion variables. Hierarchical regression was used in order to control for demographics and prior achievement. This examines the actual predictive scores of the DECA on academic achievement after accounting for demographics and prior achievement. According to Tabachnick and Fidell (2001), in hierarchical regressions, the independent variables are entered into the equation in order to assess exactly what they add to the equation.

Student absences, gender, socioeconomic status, and English proficiency were first entered into the equations as a block of demographics so as to control these variables. Second, students' academic grades from the previous years were entered into each equation in order to control for prior achievement. Finally, the DECA social and emotional factors, as the variables used to predict the academic success (grades, FCAT and SAT) were used as the criterion variables. Each criterion variable was run as a separate regression; therefore regressions were analyzed for third grade FCAT scores and NRT scores, and second grade SAT-10 scores. Regressions for each academic grade in reading and mathematics from kindergarten to third grade were also run as separate regressions to see the extent to which DECA scores predicted academic success throughout the years. 


\section{Summary}

The present study analyzed archived data that were part of a larger study.

Information from 1,978 Hispanic children living in poverty was extracted from the

databank. Regressions were then run in order to find if there was a relationship between the social and emotional development scores of these prekindergarten students and their academic success from kindergarten up until third grade. 


\section{CHAPTER IV}

\section{RESULTS}

Hypothesis: The DECA, after controlling for demographics and previous academic achievement, will predict academic success among Hispanic children from low-income families.

Various hierarchical regressions were conducted in order to evaluate how well social and emotional development in prekindergarten predicts academic success from kindergarten until third grade. Three models were run in order to control for the students' demographics as well as their prior academic achievement. The first model accounted for students' demographics (gender, days absent, socioeconomic status and English proficiency). In the second model, prior academic achievement was added to the equation (mathematics and reading grades from the previous years). Finally, the last regression model included the three predictor variables of initiative, self-control and attachment. Each regression had a different criterion variable depending on the grade and subject that was being predicted, as well as whether it was academic grades or results from a standardized test. The Bonferroni approach was used in order to control for Type I error across all the regressions, using the formula $\mathrm{p}<\alpha / \mathrm{n}-1$ in order to determine significance and $\mathrm{p}>\alpha / \mathrm{n}-1$ to determine those factors that were not significant. The results of these equations are also noted in each of the tables.

Third Grade Results

End of the year academic grades

Multiple regressions were conducted on students' third grade academic grades received at the end of the year. These were run first as the criterion variables to 
determine if the DECA factors were statistically significant in predicting academic achievement in the third grade. The results in Table 1 show how well academic achievement is predicted by demographics (model 1), previous academic achievement (model 2), and the DECA factors (model 3).

The first regression indicates that demographics accounted for a significant proportion of the students' academic mathematics grades, $\Delta R_{2}^{2}=.14, F(7,1743)=40.85$, $p<.05$. Adding the students' prior academic achievement accounted for an additional proportion of the student academic mathematics grades after controlling for demographics, $\Delta R^{2}{ }_{4}=.31, F(6,1737)=164.34, p<.05$. Finally, DECA scores did not account for any additional variance of academic grades after controlling for demographics and previous academic achievement, $\Delta R^{2}{ }_{6}=.00, F(3,1734)=.50, p>.05$. These results suggest students prior academic achievement is the most important predictor of later academic success accounting, for $31 \%$ of the variance in third grade mathematics end of the year grades.

A second regression entered the students' end of the year academic reading grades from Grade 3 as the criterion variable. As with mathematics, the first model showed demographics as a significant predictor of academic grades, $\Delta R^{2}{ }_{1}=.16, F(7,1740)=$ $.46 .36, p<.05$. The second model revealed prior academic achievement as a significant predictor of academic grades after accounting for demographics, $\Delta R_{3}^{2}=.32, F(6,1734)=$ $173.69, p<.05$. The last model, after accounting for demographics and prior academic achievement, did not account for any proportion of third grade end of the year reading achievement, $\Delta R^{2}{ }_{5}=.00, F(3,1731)=.80, p>.05$. These results suggest that prior 
Table 1

Hierarchical Regressions for Variables Predicting Third Grade End of the Year Academic Grades

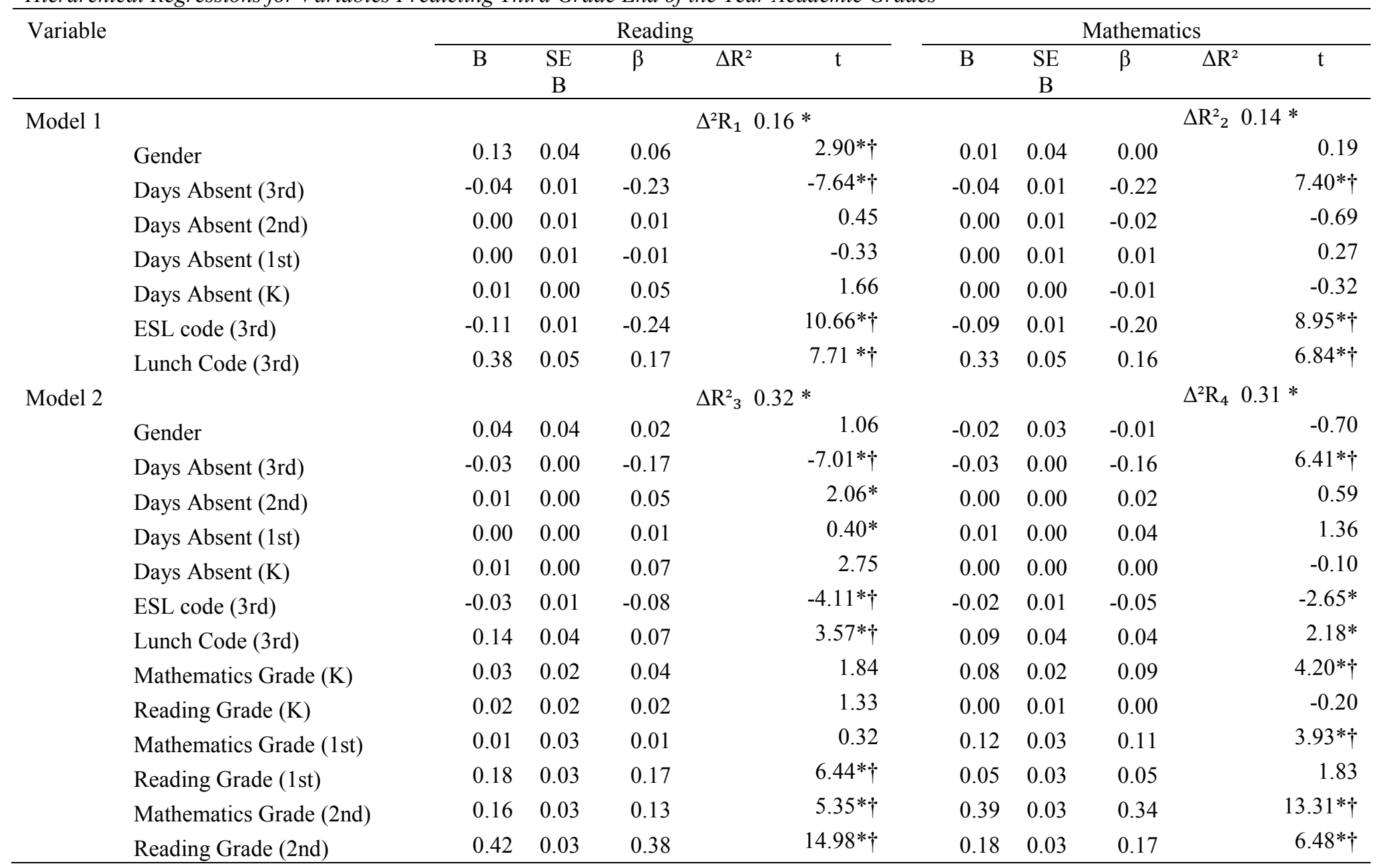

(continued) 


\begin{tabular}{|c|c|c|c|c|c|c|c|c|c|}
\hline \multirow[t]{2}{*}{ Variable } & & \multicolumn{4}{|c|}{ Reading } & \multicolumn{4}{|c|}{ Math } \\
\hline & & $\mathrm{B}$ & SE B & $\beta$ & $\mathrm{t}$ & $\mathrm{B}$ & SE B & $\beta$ & $\mathrm{t}$ \\
\hline \multirow[t]{17}{*}{ Model 3} & & & & & & & & & \\
\hline & Gender & 0.03 & 0.04 & 0.02 & 0.93 & -0.03 & 0.03 & -0.02 & $0.83 * \dagger$ \\
\hline & Days Absent (3rd) & -0.03 & 0.00 & -0.17 & $6.93 * \dagger$ & -0.03 & 0.00 & -0.16 & -6.38 \\
\hline & Days Absent (2nd) & 0.01 & 0.00 & 0.05 & $2.10^{*}$ & 0.00 & 0.00 & 0.02 & 0.63 \\
\hline & Days Absent (1st) & 0.00 & 0.00 & 0.01 & 0.37 & 0.01 & 0.00 & 0.04 & 1.34 \\
\hline & Days Absent (K) & 0.01 & 0.00 & 0.07 & $2.70^{*}$ & 0.00 & 0.00 & 0.00 & -0.13 \\
\hline & ESL code (3rd) & -0.03 & 0.01 & -0.07 & $3.91 * \dagger$ & -0.02 & 0.01 & -0.05 & $-2.54^{*}$ \\
\hline & Lunch Code (3rd) & 0.14 & 0.04 & 0.07 & $3.60 * \dagger$ & 0.09 & 0.04 & 0.04 & $2.19 *$ \\
\hline & Mathematics Grade (K) & 0.03 & 0.02 & 0.03 & 1.71 & 0.08 & 0.02 & 0.08 & $4.09 * \dagger$ \\
\hline & Reading Grade $(\mathrm{K})$ & 0.02 & 0.02 & 0.02 & 1.29 & 0.00 & 0.01 & 0.00 & -0.21 \\
\hline & Mathematics Grade (1st) & 0.01 & 0.03 & 0.01 & 0.26 & 0.12 & 0.03 & 0.10 & 3.89 \\
\hline & Reading Grade (1st) & 0.18 & 0.03 & 0.17 & $6.26^{* \dagger}$ & 0.05 & 0.03 & 0.05 & 1.67 \\
\hline & Mathematics Grade (2nd) & 0.16 & 0.03 & 0.13 & $5.33 * \dagger$ & 0.39 & 0.03 & 0.34 & $13.26^{* \dagger}$ \\
\hline & Reading Grade (2nd) & 0.42 & 0.03 & 0.37 & $14.89 * \dagger$ & 0.18 & 0.03 & 0.16 & $6.41 * \dagger$ \\
\hline & Initiative Score & 0.00 & 0.00 & 0.04 & 1.42 & 0.00 & 0.00 & 0.02 & 0.78 \\
\hline & Self Control Score & 0.00 & 0.00 & 0.00 & 0.16 & 0.00 & 0.00 & 0.01 & 0.60 \\
\hline & Attachment Score & 0.00 & 0.00 & -0.02 & -0.72 & 0.00 & 0.00 & -0.01 & -0.41 \\
\hline
\end{tabular}

Note. $\Delta \mathrm{R}^{2}{ }_{1}$ and $\Delta \mathrm{R}^{2}{ }_{2}$ is the difference between Model 1 and the null hypothesis, $\Delta \mathrm{R}^{2}{ }_{3}$ and $\Delta \mathrm{R}^{2}{ }_{4}$ is the difference between Model 1 and Model 2, $\Delta \mathrm{R}^{2}{ }_{5}$ and $\Delta \mathrm{R}^{2}{ }_{6}$ is difference between Model 2 and Model 3.

${ }^{*} \mathrm{p}<.05, \dagger$ significant after controlling for Type 1 error 
academic achievement is the main predictor for third grade end of the year reading grades, accounting for $32 \%$ of the variance.

NRT

The next set of hierarchical regressions ran examined if the DECA factors predicted the scores of the norm-referenced portion of the FCAT given in third grade. The same three models were used and the criterion variables were changed to the NRT mathematics and reading scores (see Table 2).

The results of the regression that contained the third grade NRT mathematics scores were consistent with the third grade mathematics end of the year grades. In the first model, demographics accounted for a significant proportion of the variance $\Delta R^{2}{ }_{2}=$ $.12, F(7,1764)=35.78, p<.05$. Students' prior achievement, after accounting for demographics, again revealed significance as a predictor of later academic success, $\Delta R_{4}^{2}$ $=.47, F(6,1758)=338.39, p<.05$. Finally, after accounting for demographics and previous academic achievement, the three DECA factors (model 3) accounted for no additional portion of the variance for third grade academic success as defined by the student's scores on a norm-referenced test, $\Delta R^{2}{ }_{6}=.00, F(3,1755)=1.60, p>.05$. Similar to the results of the third grade end of the year academic grades, students' prior academic achievement is the chief predictor of later academic success in regards to a norm-referenced mathematics test accounting for $47 \%$ of the variance.

The second hierarchical regression predicting third grade NRT reading scores revealed that demographics significantly predicted third grade NRT reading scores, $\Delta R^{2}{ }_{1}$ $=.14, F(7,1765)=41.96, p<.05$. After controlling for demographics, students prior academic achievement also accounted for a significant proportion of academic 
Table 2

Hierarchical Regressions for Variables Predicting Third Grade NRT Scores

\begin{tabular}{|c|c|c|c|c|c|c|c|c|c|c|}
\hline \multirow[t]{3}{*}{ Variable } & & \multicolumn{4}{|c|}{ Reading } & \multicolumn{5}{|c|}{ Mathematics } \\
\hline & & \multicolumn{3}{|c|}{ SE } & \multirow[b]{2}{*}{$\mathrm{t}$} & \multirow{2}{*}{\multicolumn{2}{|c|}{ SE B }} & \multirow{2}{*}{\multicolumn{2}{|c|}{$\Delta \mathrm{R}^{2}$}} & \multirow[b]{2}{*}{$\mathrm{t}$} \\
\hline & & $\mathrm{B}$ & $\mathrm{B}$ & & & & & & & \\
\hline \multirow[t]{8}{*}{ Model 1} & & & & & & & & & $\Delta \mathrm{R}^{2}{ }_{2} 0.12^{*}$ & \\
\hline & Gender & 1.59 & 1.51 & 0.02 & 1.05 & -7.27 & 1.82 & -0.09 & & $-3.99 * \dagger$ \\
\hline & Days Absent (3rd) & -0.90 & 0.20 & -0.13 & $4.46^{* \dagger}$ & -1.16 & 0.24 & -0.15 & & $-4.78 * \dagger$ \\
\hline & Days Absent (2nd) & 0.20 & 0.20 & 0.03 & 1.02 & -0.08 & 0.24 & -0.01 & & -0.32 \\
\hline & Days Absent (1st) & -0.08 & 0.19 & -0.01 & -0.41 & -0.08 & 0.23 & -0.01 & & -0.34 \\
\hline & Days Absent (K) & -0.05 & 0.15 & -0.01 & -0.32 & -0.11 & 0.18 & -0.02 & & -0.59 \\
\hline & ESL code (3rd) & -4.15 & 0.35 & -0.26 & $11.72 * \dagger$ & -3.93 & 0.43 & -0.21 & & $-9.23 * \dagger$ \\
\hline & Lunch Code (3rd) & 13.55 & 1.70 & 0.18 & $7.95 * \dagger$ & 14.90 & 2.05 & 0.17 & & $7.27^{* \dagger}$ \\
\hline \multirow[t]{14}{*}{ Model 2} & & & & & & & & & $\Delta^{2} \mathrm{R}_{4} 0.47^{*}$ & \\
\hline & Gender & 0.00 & 1.11 & 0.00 & 0.00 & -4.58 & 1.27 & -0.06 & & $-3.60 * \dagger$ \\
\hline & Days Absent (3rd) & -0.39 & 0.15 & -0.06 & $-2.70 * \dagger$ & -0.37 & 0.17 & -0.05 & & $-2.25^{*}$ \\
\hline & Days Absent (2nd) & 0.23 & 0.14 & 0.04 & 1.65 & -0.03 & 0.16 & 0.00 & & -0.16 \\
\hline & Days Absent (1st) & 0.18 & 0.14 & 0.03 & 1.28 & 0.27 & 0.16 & 0.04 & & 1.73 \\
\hline & Days Absent (K) & -0.03 & 0.11 & -0.01 & -0.31 & -0.10 & 0.12 & -0.02 & & -0.83 \\
\hline & ESL code (3rd) & -0.69 & 0.27 & -0.04 & $-2.57 *$ & 0.16 & 0.31 & 0.01 & & 0.53 \\
\hline & Lunch Code (3rd) & 2.82 & 1.25 & 0.04 & $2.25 *$ & 1.54 & 1.44 & 0.02 & & 1.08 \\
\hline & Mathematics Grade (K) & 1.05 & 0.58 & 0.03 & 1.80 & 2.60 & 0.67 & 0.07 & & $3.88 * \dagger$ \\
\hline & Mathematics Grade (1st) & 0.00 & 1.00 & 0.00 & 0.00 & 6.33 & 1.14 & 0.13 & & $5.53 * \dagger$ \\
\hline & Reading Grade (K) & 0.42 & 0.47 & 0.01 & 0.88 & 0.26 & 0.54 & 0.01 & & 0.49 \\
\hline & Reading Grade (1st) & 6.25 & 0.89 & 0.17 & $6.99 * \dagger$ & 1.30 & 1.02 & 0.03 & & 1.27 \\
\hline & SAT (2nd Mathematics) & 0.11 & 0.02 & 0.13 & $5.74 * \dagger$ & 0.44 & 0.02 & 0.45 & & $20.45^{* \dagger}$ \\
\hline & SAT (2nd Reading) & 0.45 & 0.02 & 0.50 & $21.59 * \dagger$ & 0.25 & 0.02 & 0.23 & & $10.44 * \dagger$ \\
\hline
\end{tabular}

(continued) 


\begin{tabular}{|c|c|c|c|c|c|c|c|c|c|c|c|}
\hline \multirow[t]{2}{*}{ Variable } & & \multicolumn{5}{|c|}{ Reading } & \multicolumn{5}{|c|}{ Math } \\
\hline & & $\mathrm{B}$ & SE B & $\beta$ & $\Delta \mathrm{R}^{2}$ & $\mathrm{t}$ & B & SE B & $\beta$ & $\Delta \mathrm{R}^{2}$ & $\mathrm{t}$ \\
\hline \multirow{17}{*}{ Model 3} & & & & & $\Delta \mathrm{R}^{2}{ }_{5} 0 . \mathrm{C}$ & & & & & $\Delta \mathrm{R}^{2}{ }_{6} 0.00$ & \\
\hline & Gender & -0.02 & 1.13 & 0.00 & & -0.02 & -4.59 & 1.29 & -0.06 & & $-3.55^{*} \dagger$ \\
\hline & Days Absent (3rd) & -0.38 & 0.15 & -0.06 & & $-2.63 *$ & -0.36 & 0.17 & -0.04 & & $-2.14 *$ \\
\hline & Days Absent (2nd) & 0.23 & 0.14 & 0.04 & & 1.67 & -0.02 & 0.16 & 0.00 & & -0.12 \\
\hline & Days Absent (1st) & 0.17 & 0.14 & 0.03 & & 1.24 & 0.27 & 0.16 & 0.04 & & 1.70 \\
\hline & Days Absent (K) & -0.03 & 0.11 & -0.01 & & -0.28 & -0.10 & 0.12 & -0.02 & & -0.82 \\
\hline & ESL code (3rd) & -0.66 & 0.27 & -0.04 & & $-2.42 *$ & 0.23 & 0.31 & 0.01 & & 0.75 \\
\hline & Lunch Code (3rd) & 2.83 & 1.26 & 0.04 & & $2.25^{*}$ & 1.65 & 1.44 & 0.02 & & 1.15 \\
\hline & Mathematics Grade (K) & 1.04 & 0.59 & 0.03 & & 1.77 & 2.53 & 0.67 & 0.07 & & $3.76 * \dagger$ \\
\hline & Mathematics Grade (1st) & -0.04 & 1.00 & 0.00 & & -0.04 & 6.28 & 1.15 & 0.13 & & $5.48^{* \dagger}$ \\
\hline & Reading Grade (K) & 0.40 & 0.48 & 0.01 & & 0.83 & 0.21 & 0.54 & 0.01 & & 0.38 \\
\hline & Reading Grade (1st) & 6.29 & 0.90 & 0.17 & & $6.97 * \dagger$ & 1.31 & 1.03 & 0.03 & & 1.27 \\
\hline & SAT (2nd Mathematics) & 0.11 & 0.02 & 0.13 & & $5.66 * \dagger$ & 0.44 & 0.02 & 0.45 & & $20.24 * \dagger$ \\
\hline & SAT (2nd Reading) & 0.45 & 0.02 & 0.50 & & $21.56 * \dagger$ & 0.25 & 0.02 & 0.23 & & $10.42 * \dagger$ \\
\hline & Initiative Score & 0.07 & 0.08 & 0.02 & & 0.80 & 0.20 & 0.10 & 0.05 & & $2.08^{*}$ \\
\hline & Self Control Score & -0.06 & 0.08 & -0.02 & & -0.80 & -0.08 & 0.09 & -0.02 & & -0.98 \\
\hline & Attachment Score & -0.01 & 0.09 & 0.00 & & -0.12 & -0.11 & 0.10 & -0.03 & & -1.09 \\
\hline
\end{tabular}

Note. $\Delta \mathrm{R}^{2}{ }_{1}$ and $\Delta \mathrm{R}^{2}{ }_{2}$ is the difference between Model 1 and the null hypothesis, $\Delta \mathrm{R}^{2}{ }_{3}$ and $\Delta \mathrm{R}^{2}{ }_{4}$ is the difference between Model 1 and Model 2, $\Delta \mathrm{R}^{2}{ }_{5}$ and $\Delta \mathrm{R}^{2}{ }_{6}$ is difference between Model 2 and Model 3.

${ }^{*} \mathrm{p}<.05, \dagger$ significant after controlling for Type 1 error 
achievement in third grade NRT reading, $\Delta R^{2}{ }_{3}=.42, F(6,1759), p<.05$. Finally, after accounting for both demographics and prior academic achievement, the DECA scores revealed no significance in predicting third grade NRT reading scores, $\Delta R^{2}{ }_{5}=.00, F(3$, $1756)=.37, p>.05$. These results suggest that students' previous academic achievement is the most important predictor of third grade NRT reading scores accounting for $42 \%$ of the variance after demographics were accounted for.

FCAT

The results for the hierarchical regressions predicting third grade FCAT scores can be found in Table 3. These regressions adhered to the same three models as the third grade NRT scores and third grade academic grades. The criterion variable was changed to third grade FCAT scores and the order in which the predictor variables were added to the equation stayed the same.

Demographics was a significant predictor of both mathematics, $\Delta R^{2}{ }_{2}=.15, F(7$, $1765)=42.85, p<.05$, and reading, $\Delta R^{2}{ }_{1}=.12, F(7,1766)=35.26, p<.05$, FCAT scores. After controlling for demographics, students' previous academic achievement accounted for a significant proportion of FCAT scores for both mathematics, $\Delta R_{4}^{2}=.41$, $F(6,1759)=268.40, p<.05$, and reading, $\Delta R^{2}{ }_{3}=.42, F(6,1760)=274.14, p<.05$. The last model inserted the three DECA factors into the equation revealed that the DECA factors were not significant for mathematics, $\Delta R^{2}{ }_{6}=.00, F(3,1756)=.93, p>.05$, or reading, $\Delta R^{2}{ }_{5}=.00, F(3,1757)=.67, p>.05$ scores. The results of the third grade FCAT mathematics scores were consistent with the previous third grade regressions in that students' prior academic achievement was the most important predictor for FCAT 
Table 3

Hierarchical Regressions for Variables Predicting Third Grade FCAT scores

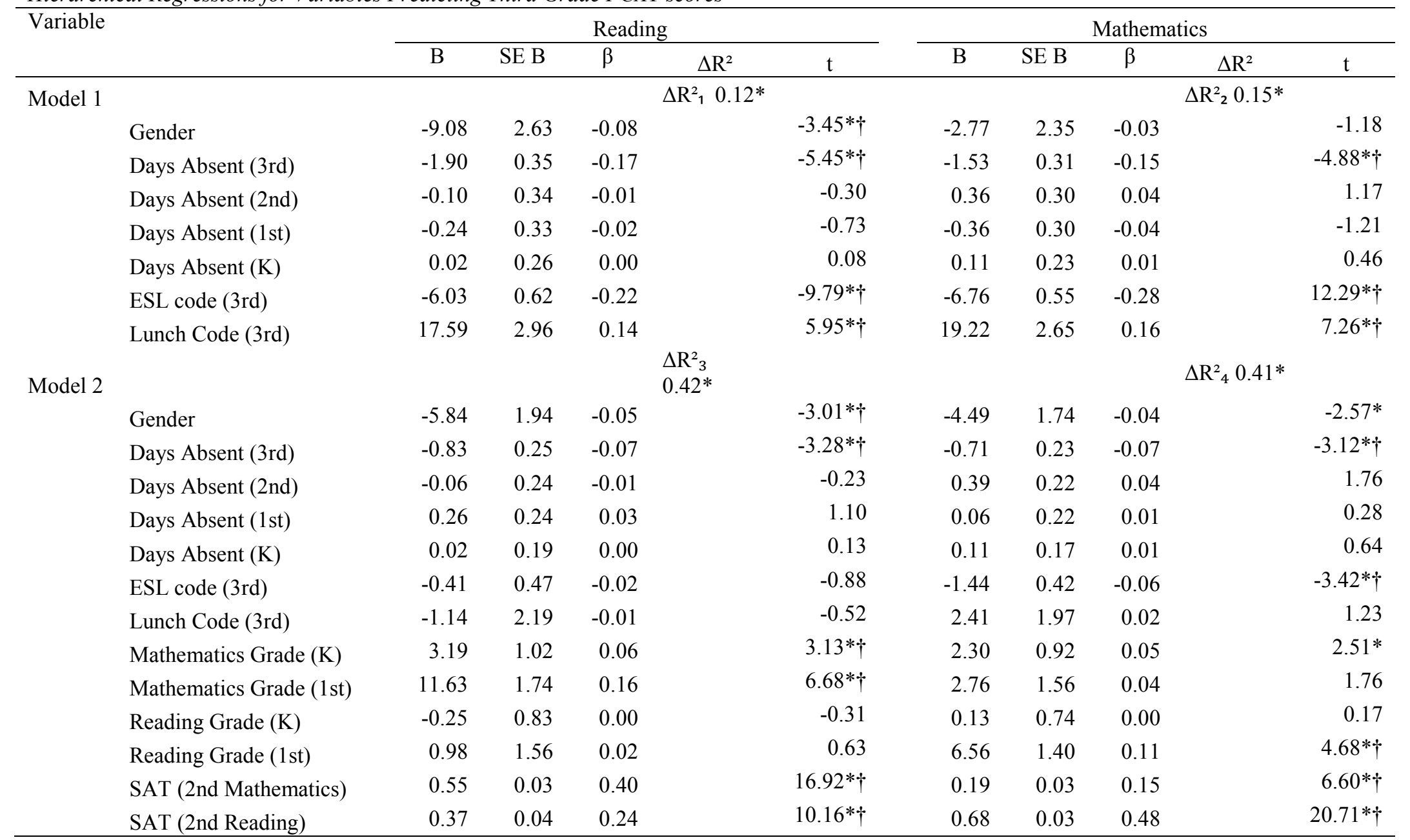

(continued) 
Table 3 (continued)

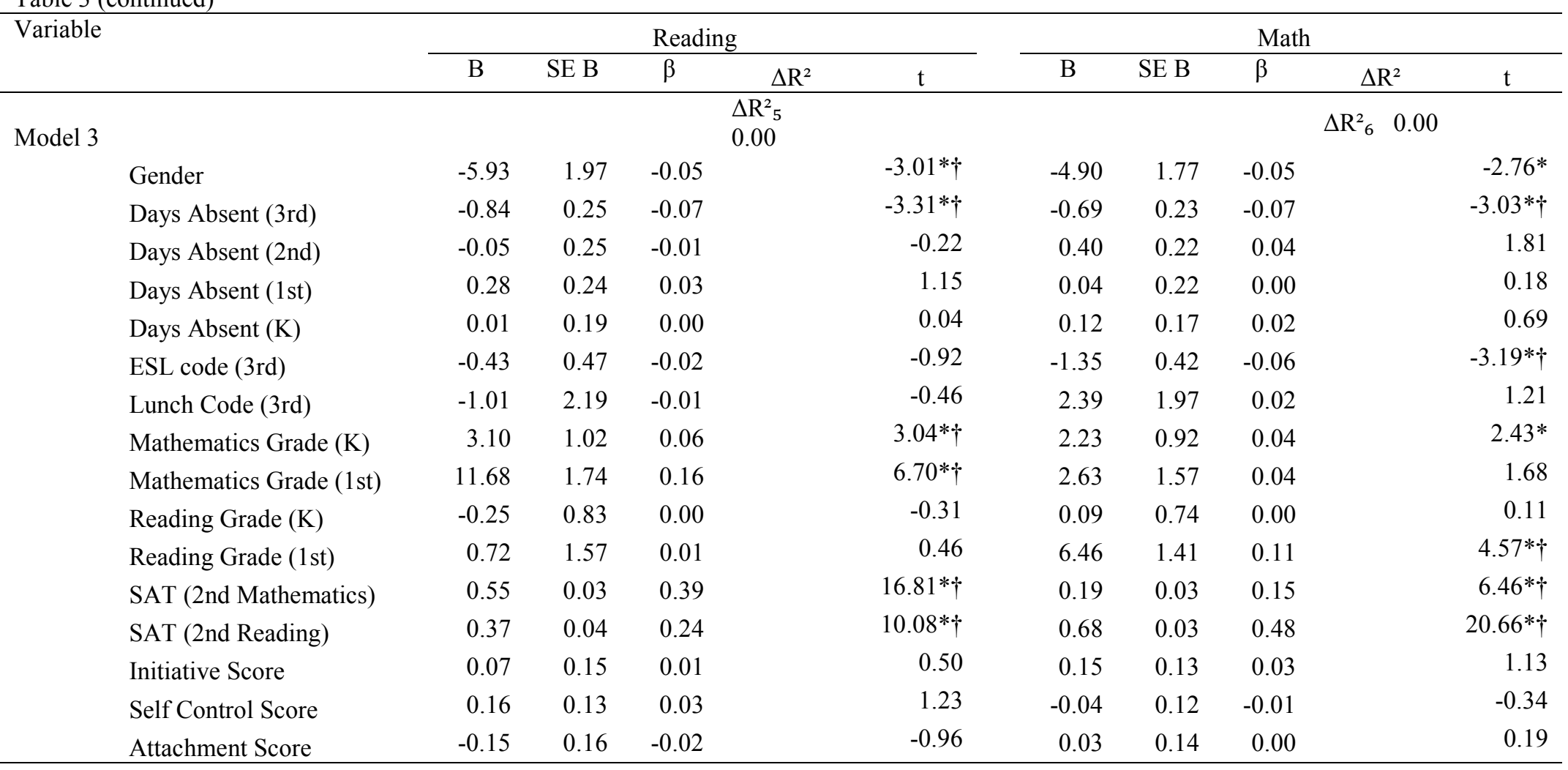

Note. $\Delta \mathrm{R}^{2}{ }_{1}$ and $\Delta \mathrm{R}^{2}{ }_{2}$ is the difference between Model 1 and the null hypothesis, $\Delta \mathrm{R}^{2}{ }_{3}$ and $\Delta \mathrm{R}^{2}{ }_{4}$ is the difference between

Model 1 and Model 2, $\Delta \mathrm{R}^{2}{ }_{5}$ and $\Delta \mathrm{R}^{2}{ }_{6}$ is difference between Model 2 and Model 3.

${ }^{*} \mathrm{p}<.05, \dagger$ significant after controlling for Type 1 error 
scores accounting for $41 \%$ of the variance in mathematics and $42 \%$ of the variance in reading.

\section{Second Grade Results}

\section{End of the year academic grades}

After analyzing all the third grade criterion variables, the decision was made to examine the DECA factors as predictors for second grade success because there was no significance in third grade. The same three models were used on order to control for demographics and prior academic achievement. Table 4 provides the results of the hierarchical regression predicting second grade academic success from the DECA factors.

Multiple regressions were conducted with second grade mathematics and reading grades as the criterion variables. The first model revealed demographics as a significant predictor of second grade mathematics, $\Delta R^{2}{ }_{2}=.10, F(6,1769)=31.47, p<.05$, and reading, $\Delta R^{2}{ }_{1}=.12, F(6,1770)=39.06, p<.05$. After controlling for demographics, students' prior academic achievement also showed significance in both mathematics, $\Delta R^{2}{ }_{4}=.29, F(4,1765)=207.50, p<.05$, and reading, $\Delta R^{2}{ }_{3}=.28, F(4,1766)=205.41, p$ $<.05$. The third model, again revealed that the DECA factors were not significant predictors for mathematics, $\Delta R^{2}{ }_{6}=.00, F(3,1762)=2.65, p>.05$, or reading, $\Delta R^{2}{ }_{5}=$ $.00, F(3,1763)=3.26, p>.05$, grades after accounting for demographics and prior achievement. The results of the hierarchical regressions for end of the year second grade academic grades suggest that students' prior academic achievement is the most important predictor in second grade accounting for $29 \%$ of the variance in mathematics and $28 \%$ of the variance in reading, implying that students who are academically successful in 
Table 4

Hierarchical Regressions for Variables Predicting Second Grade End of the Year Academic Grades

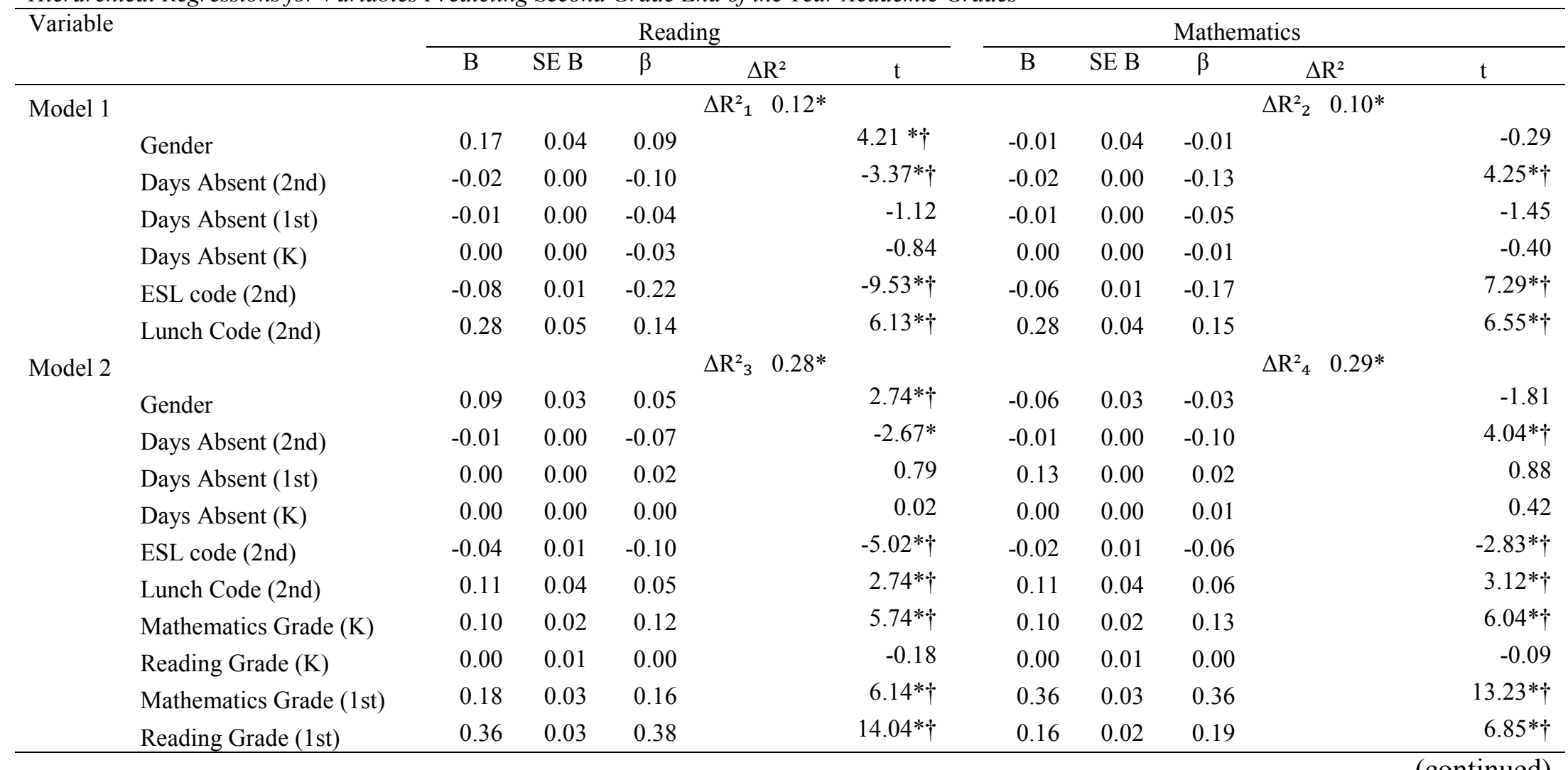


Table 4 (continued)

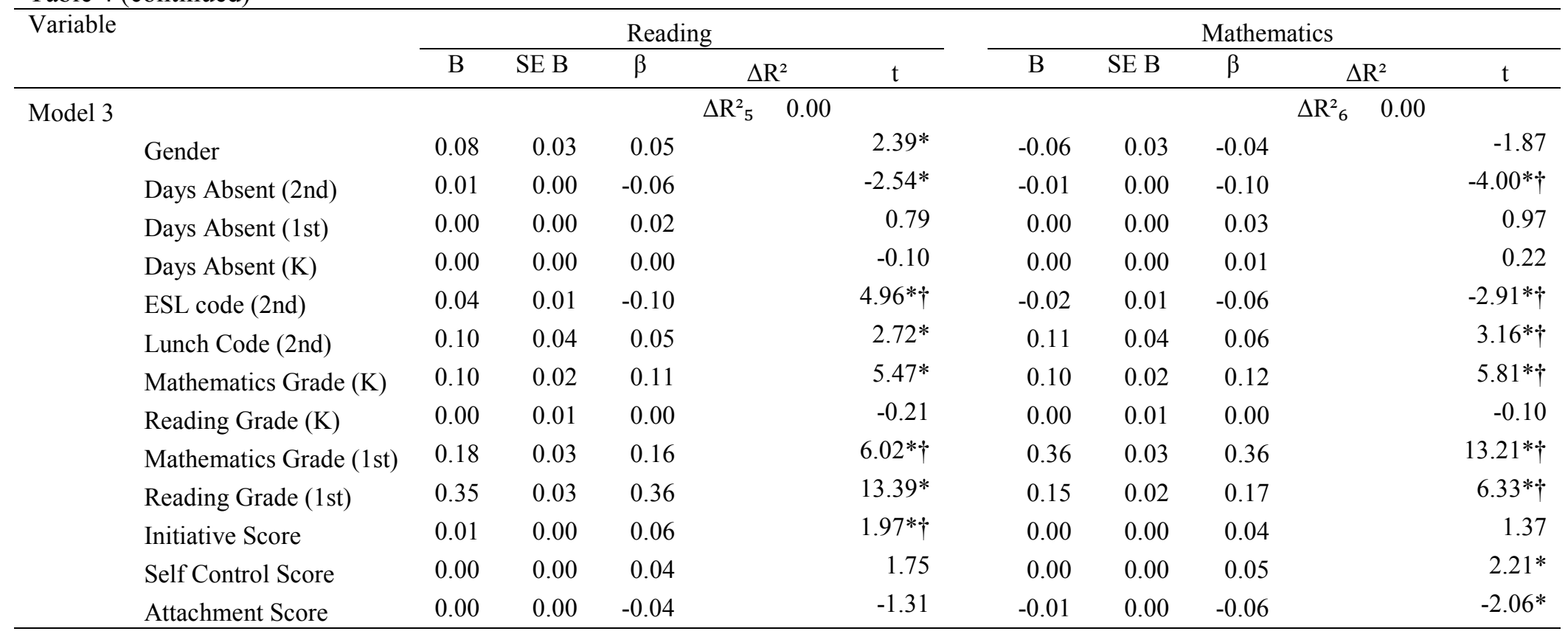

Note. $\Delta \mathrm{R}^{2}{ }_{1}$ and $\Delta \mathrm{R}^{2}{ }_{2}$ is the difference between Model 1 and the null hypothesis, $\Delta \mathrm{R}^{2}{ }_{3}$ and $\Delta \mathrm{R}^{2}{ }_{4}$ is the difference between

Model 1 and Model 2, $\Delta \mathrm{R}^{2}{ }_{5}$ and $\Delta \mathrm{R}^{2}{ }_{6}$ is difference between Model 2 and Model 3.

$* \mathrm{p}<.05, \dagger$ significant after controlling for Type 1 error 
previous years will continue to be academically successful. This is also evident from the third grade results.

SAT-10

After analyzing the regressions of the variables predicting the mathematics and reading academic grades of second grade, SAT scores were examined in order find the predictive value of the DECA factors on a second grade standardized test (see Table 5). Second grade SAT scores were entered as the criterion variables and the three models remained in order to control for demographics and prior achievement.

The results of the first model indicate that demographics account for a significant amount of second grade mathematics, $\Delta R^{2}{ }_{2}=.11, F(6,1769)=37.47, p<.05$, and reading, $\Delta R^{2}{ }_{1}=.14, F(6,1770)=47.69, p<.05$, SAT scores. The second analysis was conducted to examine how students' prior academic achievement predicted second grade SAT scores above and beyond demographics. Students' previous academic achievement was found to account for a significant amount of the variance for both mathematics, $\Delta R^{2}{ }_{4}$ $=.26, F(4,1765)=185.98, p<.05$, and reading, $\Delta R^{2}{ }_{3}=.24, F(4,1766)=172.26, p$ $<.05$, after controlling for demographics. The last model was carried out to study the predictive power of the DECA factors above and beyond demographics and students' prior academic success. This analysis revealed that the DECA factors predict second grade mathematics, $\Delta R^{2}{ }_{6}=.01, F(3,1762)=8.14, p<.05$, and reading, $\Delta R^{2}{ }_{5}=$ $.01, F(3,1763)=5.10, p<.05$, SAT scores above and beyond demographics and prior achievement.

These results suggest again that students who are high achievers in the previous years will continue to be high achievers; accounting for $26 \%$ of the variance for 
Table 5

Hierarchical Regressions for Variables Predicting Second Grade SAT Scores

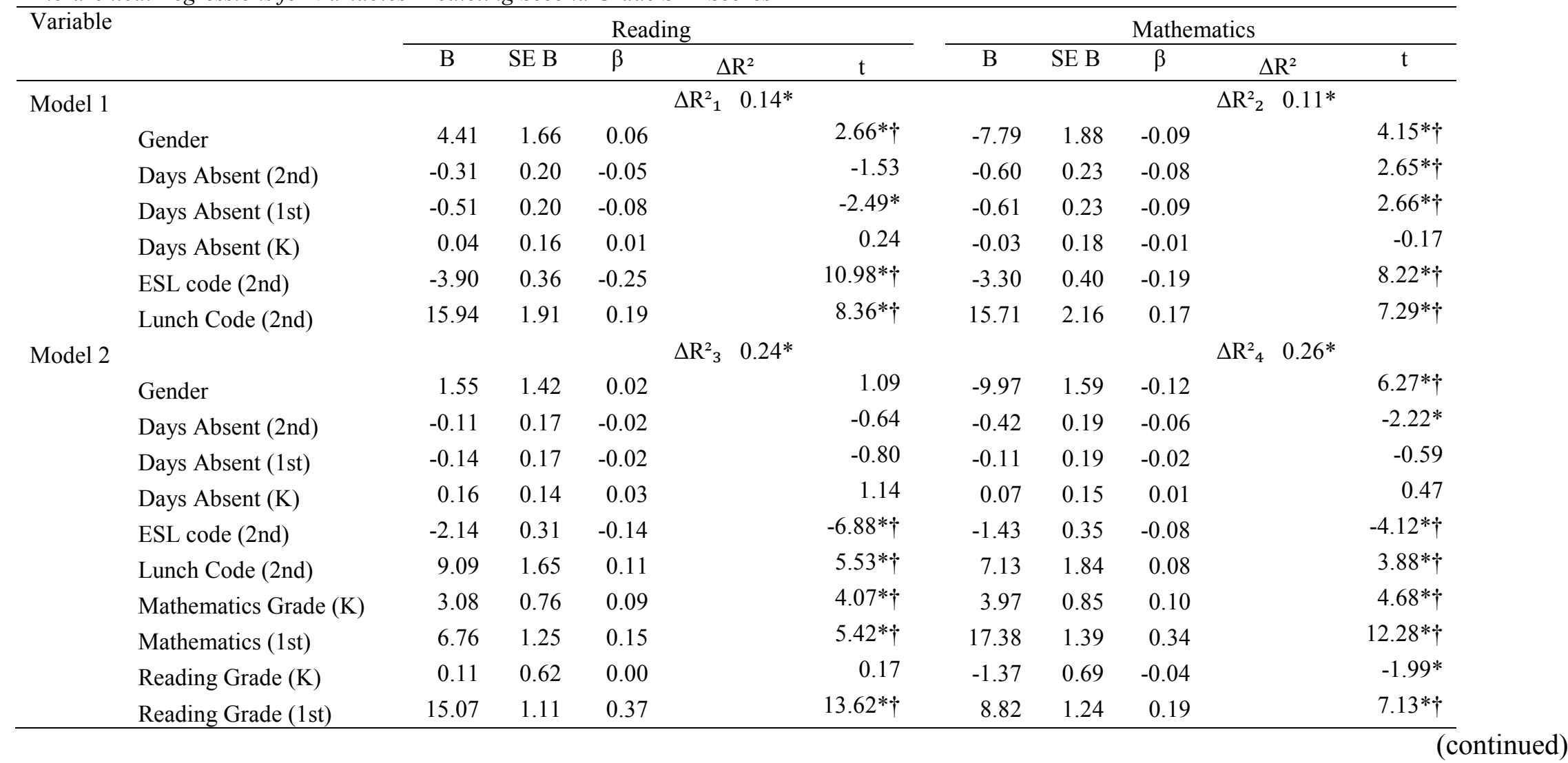


Table 5 (continued)

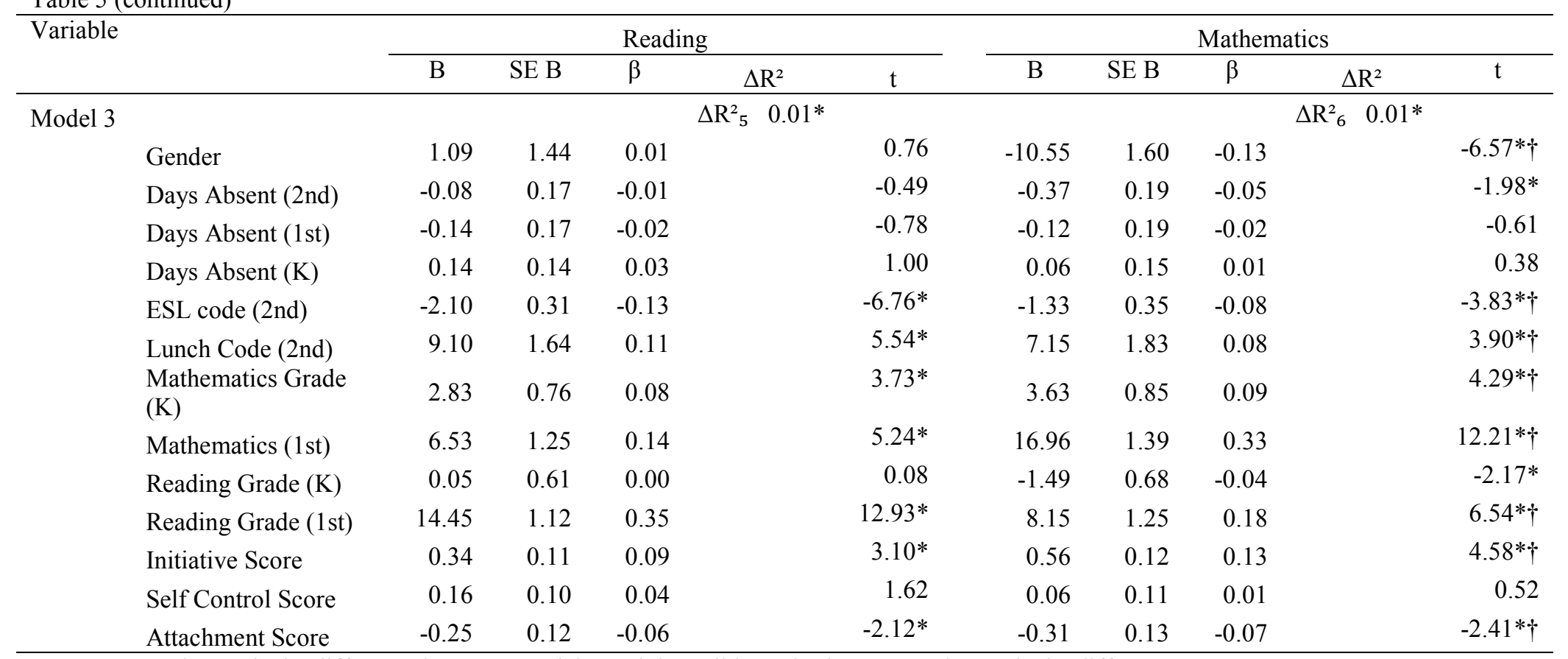

Note. $\Delta \mathrm{R}^{2}{ }_{1}$ and $\Delta \mathrm{R}^{2}{ }_{2}$ is the difference between Model 1 and the null hypothesis, $\Delta \mathrm{R}^{2}{ }_{3}$ and $\Delta \mathrm{R}^{2}{ }_{4}$ is the difference

between

Model 1 and Model 2, $\Delta \mathrm{R}_{5}{ }_{5}$ and $\Delta \mathrm{R}^{2}{ }_{6}$ is difference between Model 2 and Model 3.

${ }^{*} \mathrm{p}<.05, \uparrow$ significant after controlling for Type 1 error 
mathematics and $24 \%$ of the variance for reading. In these hierarchical regressions, the DECA factors did show minor significance accounting for $1 \%$ of the variance in both mathematics and reading.

\section{First Grade Results}

The DECA factors demonstrated a small predictive value for first grade academic achievement. These results suggest that the DECA factors may be more predictive in the lower grades when there is not as much variance accounted for by prior academic achievement. Table 6 shows the results when first grade mathematics and reading end of the year academic grades were used as the criterion variables.

The first analysis was conducted to account for demographics as a predictive value for first grade success. The results, similar to the previous second and third grade results, showed demographics accounting for a significant proportion of mathematics, $\Delta R^{2}{ }_{2}=.08, F(5,1825)=31.96, p<.05$, and reading, $\Delta R^{2}{ }_{1}=.08, F(5,1791)=33.04, p<$ .05. The second model, controlling for demographics and adding prior achievement to the equation, demonstrated significant proportions of variance for both mathematics, $\Delta R^{2}{ }_{4}=.15, F(2,1823)=170.52, p<.05$, and reading, $\Delta R^{2}{ }_{3}=.14, F(2,1789)=154.79, p$

$<.05$. After controlling for demographics and prior achievement, the DECA factors significantly predicted a small portion of first grade success in mathematics, $\Delta R^{2}{ }_{6}=.03$, $F(3,1820)=21.37, p<.05$, and reading, $\Delta R^{2}{ }_{5}=.05, F(3,1786)=36.15, p<.05$.

The results of the first grade hierarchical regression continue to suggest that prior academic achievement is the main predictor of academic success accounting for $15 \%$ of the variance in first grade mathematics and $14 \%$ of the variance for reading. However, the results show that as prior academic achievement accounts for less of the variance, the 
Table 6

Hierarchical Regressions for Variables Predicting First Grade End of the Year Academic Grades

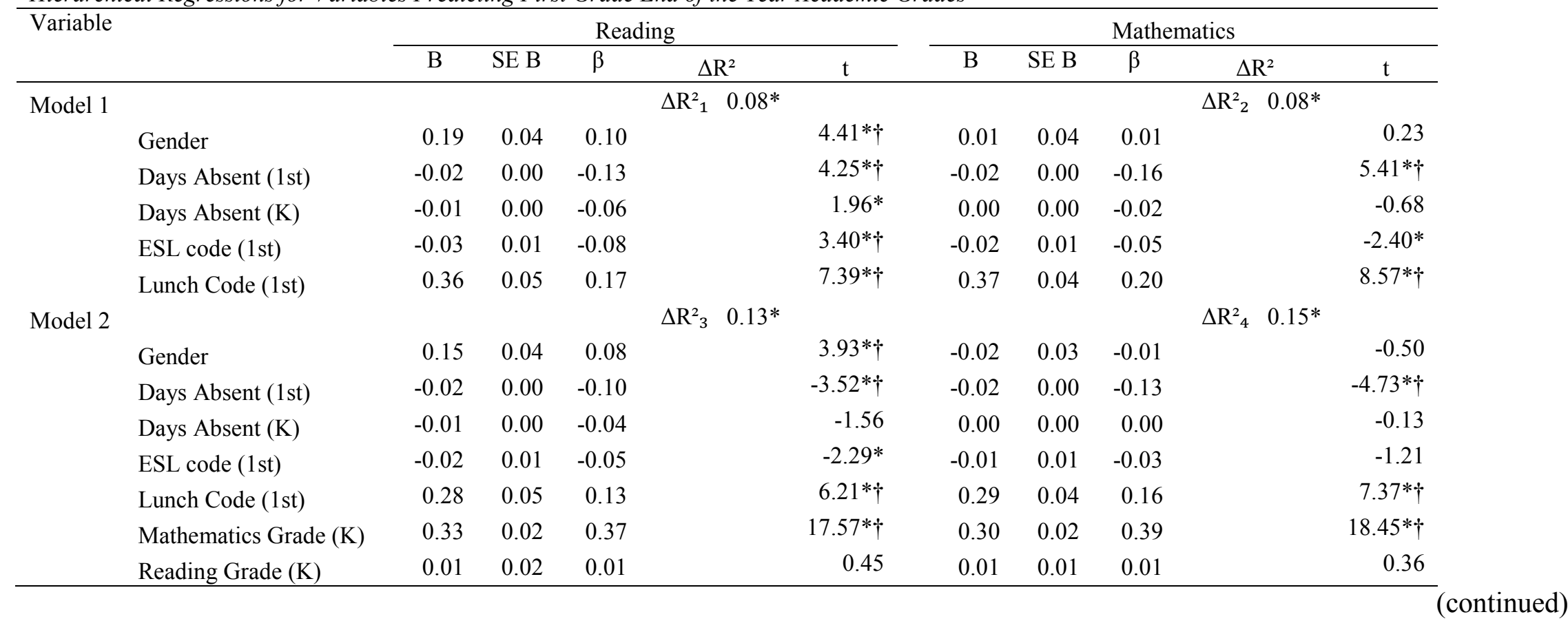


Table 6 (continued)

\begin{tabular}{|c|c|c|c|c|c|c|c|c|c|c|c|}
\hline \multirow[t]{2}{*}{ Variable } & & \multicolumn{5}{|c|}{ Reading } & \multicolumn{5}{|c|}{ Mathematics } \\
\hline & & B & SE B & $\beta$ & $\Delta \mathrm{R}^{2}$ & $\mathrm{t}$ & B & SE B & $\beta$ & $\Delta \mathrm{R}^{2}$ & $\mathrm{t}$ \\
\hline \multirow[t]{11}{*}{ Model 3} & & \multicolumn{5}{|c|}{$\Delta \mathrm{R}^{2}{ }_{5} \quad 0.05^{*}$} & & & \multicolumn{3}{|c|}{$\Delta \mathrm{R}^{2}{ }_{6} \quad 0.03^{*}$} \\
\hline & Gender & 0.10 & 0.04 & 0.05 & & $2.63 *$ & -0.05 & 0.03 & -0.03 & & -1.60 \\
\hline & Days Absent (1st) & 0.01 & 0.00 & -0.09 & & $-3.28 *$ & -0.02 & 0.00 & -0.12 & & $-4.54 * \dagger$ \\
\hline & Days Absent (K) & 0.01 & 0.00 & -0.05 & & -1.75 & 0.00 & 0.00 & -0.01 & & -0.19 \\
\hline & ESL code (1st) & 0.02 & 0.01 & -0.05 & & $-2.35^{*}$ & -0.01 & 0.01 & -0.02 & & -1.09 \\
\hline & Lunch Code (1st) & 0.27 & 0.04 & 0.13 & & $6.12 * \dagger$ & 0.28 & 0.04 & 0.15 & & $7.15^{* \dagger}$ \\
\hline & Mathematics Grade (K) & 0.29 & 0.02 & 0.33 & & $15.63 * \dagger$ & 0.28 & 0.02 & 0.35 & & $16.76^{* \dagger}$ \\
\hline & Reading Grade $(\mathrm{K})$ & 0.01 & 0.02 & 0.01 & & 0.34 & 0.00 & 0.01 & 0.00 & & 0.18 \\
\hline & Initiative Score & 0.02 & 0.00 & 0.18 & & $5.84 * \dagger$ & 0.01 & 0.00 & 0.17 & & $5.40 * \dagger$ \\
\hline & Self Control Score & 0.01 & 0.00 & 0.15 & & $5.72 * \dagger$ & 0.01 & 0.00 & 0.07 & & $2.55^{*}$ \\
\hline & Attachment Score & 0.01 & 0.00 & -0.10 & & $-3.23^{*}$ & 0.00 & 0.00 & -0.06 & & -1.77 \\
\hline
\end{tabular}

Note. $\Delta \mathrm{R}^{2}{ }_{1}$ and $\Delta \mathrm{R}^{2}{ }_{2}$ is the difference between Model 1 and the null hypothesis, $\Delta \mathrm{R}^{2}{ }_{3}$ and $\Delta \mathrm{R}^{2}{ }_{4}$ is the difference between

Model 1 and Model 2, $\Delta \mathrm{R}_{5}^{2}$ and $\Delta \mathrm{R}^{2}{ }_{6}$ is difference between Model 2 and Model 3.

${ }^{*} \mathrm{p}<.05, \dagger$ significant after controlling for Type 1 error 
DECA factors begin to account for a more significant proportion of academic success in mathematics, $3 \%$ of the variance, and reading, $5 \%$ of the variance.

\section{Kindergarten Results}

The multiple regressions in kindergarten were based on only two models since there are no prior academic grades. Therefore model 1 examines how well academic achievement is predicted by demographics and model 2 shows how well the DECA factors predict academic achievement after accounting for demographics (see Table 7).

In the first regression, the first set of predictors, demographics, accounted for a significant proportion of the students' kindergarten mathematics grade, $\Delta R^{2}{ }_{2}=.03, F(4$, $1926)=15.00, p<.05$, but not their reading grade, $\Delta R^{2}{ }_{1}=.00, F(4,1909)=.80, p>.05$. The second analysis, after controlling for demographics, revealed that the DECA factors account for a significant proportion of kindergarten academic success in mathematics, $\Delta R^{2}{ }_{4}=.04, \mathrm{~F}(3,1923)=27.98, \mathrm{p}<.05$, but not in reading, $\Delta R^{2}{ }_{3}=.00, F(3,1906)=.54$, $p>.05$. These results suggest that the DECA factors account for $4 \%$ of the significant variance in their kindergarten mathematics grade, but do not account for any significant variance in their reading grade.

\section{Summary}

This chapter presented an analysis of the data related to the three DECA factors as predictor variables for academic success. Hierarchical regressions were used to analyze the data for relationships between the DECA factors and FCAT scores, SAT scores and academic grades from kindergarten to grade three. 
Table 7

Hierarchical Regressions for Variables Predicting Kindergarten End of the Year Academic Grades

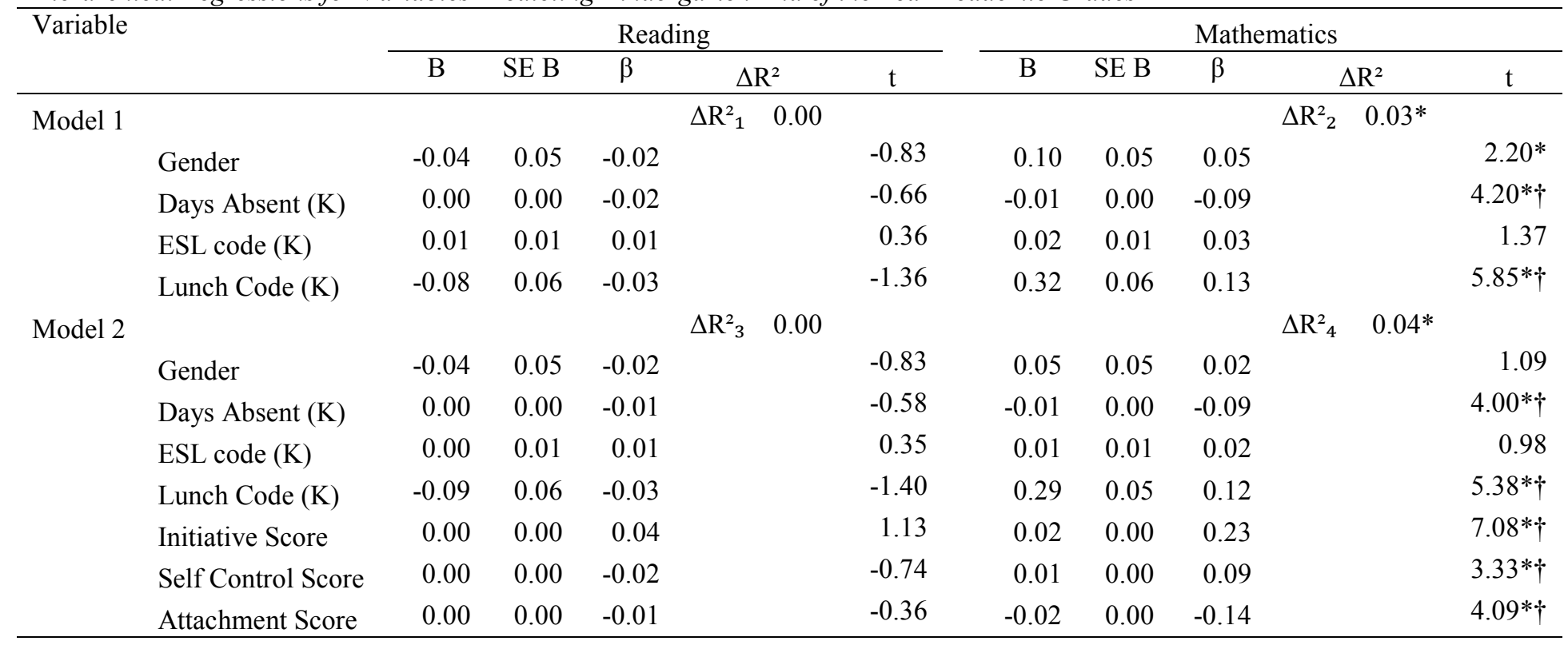

Note. $\Delta \mathrm{R}^{2}{ }_{1}$ and $\Delta \mathrm{R}^{2}{ }_{2}$ is the difference between Model 1 and the null hypothesis, $\Delta \mathrm{R}^{2}{ }_{3}$ and $\Delta \mathrm{R}^{2}{ }_{4}$ is the difference between

Model 1 and Model 2.

${ }^{*} \mathrm{p}<.05, \dagger$ significant after controlling for Type 1 error 
The hierarchical regressions revealed that students' prior academic achievement accounted for a significant proportion of the following criterion variables: third grade reading and mathematics grades, FCAT scores and NRT sores; second grade reading and mathematics grades and SAT scores; first grade reading and mathematics grades. The only exception was the kindergarten grades because there is no prior academic achievement to account for. These results suggest that a student who has high academic grades will continue to achieve academically at least until third grade.

The findings derived from the hierarchical regressions suggest that the DECA factors do not account for any of the variance of the students' third grade reading and mathematics grades, NRT scores or FCAT scores. The DECA factors were found to account for a very small proportion of variance in the models that contained second grade SAT scores, first and second grade academic grades and kindergarten mathematics grades. 


\section{CHAPTER V \\ DISCUSSION}

In early childhood education, much attention is spent on teaching to "the whole child." The whole child is code for focusing on social and emotional development as well as cognitive and academic content (Zigler \& Bishop-Josef, 2006). Early childhood educators have long felt that making intellectual gains at the expense of social and emotional development was not worthwhile. Further, they felt that children who did not have a good foundation of social skills and morals would not be able to fulfill their academic promise or use it to good ends (Johnson, Gallagher, Cook, \& Wong, 1995; Lin, Lawrence, \& Gorrell, 2003; McAllister, Wilson, Green, \& Baldwin, 2005; Piotrkowski, Botsko, \& Matthews, 2000; Wesley \& Buysse, 2003).

Researchers in the area of children's initiative, self-control, and attachment have also been interested in how these competencies facilitate academic learning and have been able to show the positive outcome of social and emotional development within the early years (Agostin \& Bain, 1997; Bandura, 2000; Bandura \& Mischel,1965; Lin et al., 2003; Slaughter-Defoe \& Rubin, 2001; Spieker, Nelson, Petras, Jolley, \& Barnard, 2003; Sroufe, 1983; Turner \& Johnson, 2003). Though much research has been conducted showing that these constructs are real, and actualized, and important for children's performance and enjoyment of early childhood education, very little research has been able to link social and emotional development with academic success in the early elementary years. In addition, few of the studies have focused specifically on Hispanics, whose social and emotional development may or may not conform to that of overall norms. 
The main rationale for this study was to see if evidence for such long-term relationships between social and emotional development and academic success could be found in a unique database. The opportunity arose to try to answer the question of whether the data supported the hypothesis for long-term relationships between social and emotional development and academic success.

The outcomes, as reported in chapter 4, did not definitively answer the research question. It was expected that initiative, attachment and self-control would have a significant predictive value on academic achievement and account for a larger percent of the variance. Children's DECA scores at age four did predict some of the academic outcomes in kindergarten and first grade, but their predictive power weakened with each subsequent year until they showed no relation at third grade. However, students' prior academic achievement had the greatest relationship with academic outcomes and accounted for the majority of the variance.

The hypothesis tested was that there would be a relationship between social and emotional development (as measured by the three factors of the DECA) and academic success in kindergarten through third grade. Unlike O'Connor and McCartney (2007), who found that children with secure attachments to their teachers did better on academic achievement in third grade, this study did not find any relationships between the DECA and third grade outcomes (FCAT, NRT, and end of the year grades) or any of the variance in the second grade end of the year math and reading grades. The DECA measures the level of closeness a child has to an adult, whether it is a teacher or parent. After conducting the hierarchical regressions and finding such low predictive values for the DECA factors, a correlational analysis was run to determine the strength of 
the relationships between the predictor variables (DECA factors) and the criterion variables (academic achievement). The main reason the results of this study did not support the hypothesis was due to the fact that the correlations between the three DECA factors and all the academic achievement variables, although significant, were low (see Table 8). The highest correlation of .272 at $p<.01$ was between initiative and end of the year first reading grade. The correlations between the three DECA factors were high indicating multicolinearity between the variables, which reduces the power of the three individual variables.

These results show the difficulty of linking the social and emotional development of prekindergarten children to academic achievement in elementary school. One of the reasons the results may not have shown a greater association between the DECA and academic achievement in third grade and second grade end of the year grades could be due to the fact that the students were assessed at age four. By the time they reached second and third grade, 3 to 4 years had passed since the assessment. Social and emotional development may not be a stable construct and may be affected by changes in a child's environment (Cooper, Masi, \& Vick, 2009). A child who demonstrated high social skills in prekindergarten may have developed risk factors (e.g., divorce, death, introduction of a new family or changing schools) after entering elementary school which would have then in turn affected his/her social development and academic performance. The same is true for a child whose life may have been in turmoil during prekindergarten, but become stable throughout elementary school. 
Table 8

Correlations Between DECA Factors and Academic Achievement

\begin{tabular}{|c|c|c|c|}
\hline Variables & Initiative & Self Control & Attachment \\
\hline Initiative & 1.000 & & \\
\hline Self-Control & $.523 * *$ & 1.000 & \\
\hline Attachment & $.731 * *$ & $.587 * *$ & 1.000 \\
\hline Math Grade (K) & $.199 * *$ & $.141 * *$ & $.105 * *$ \\
\hline Reading Grade (K) & 0.013 & -0.013 & -0.004 \\
\hline Math Grade (1st) & $.243 * *$ & $.170 * *$ & $.152 * *$ \\
\hline Reading Grade (1st) & $.272 * *$ & $.236 * *$ & $.172 * *$ \\
\hline Math Grade (2nd) & $.208 * *$ & $.178 * *$ & $.123 * *$ \\
\hline Reading Grade (2nd) & $.240 * *$ & $.200 * *$ & $.162 * *$ \\
\hline SAT (2nd Math) & $.238 * *$ & $.133 * *$ & $.120 * *$ \\
\hline SAT (2nd Reading) & $.243 * *$ & $.174 * *$ & $.146^{* *}$ \\
\hline Math Grade (3rd) & $.201 * *$ & $.151 * *$ & $.123 * *$ \\
\hline Reading Grade (3rd) & $.233 * *$ & $.165 * *$ & $.150 * *$ \\
\hline NRT (3rd Math) & $.226 * *$ & $.128 * *$ & $.111 * *$ \\
\hline NRT (3rd Reading) & $.227 * *$ & $.153 * *$ & $.135 * *$ \\
\hline FCAT (3rd Math) & $.229 * *$ & $.151 * *$ & $.138 * *$ \\
\hline FCAT (3rd Reading) & $.215^{* *}$ & $.157^{* *}$ & $.116^{* *}$ \\
\hline
\end{tabular}

If social and emotional traits do remain constant, then the best explanation for these results is that they do not have much if any effect on academic performance. If this were the case then the best way to increase academic performance would be to focus on the discipline content and not be that concerned about the child's social and emotional development. This explanation would also bring into question the practice of assessing children for social and emotional development in preschool at age four, if these traits either are likely to change or have no bearing on future academic performance.

The DECA factors, while not the strongest predictors of academic success from kindergarten through third grade, did account for a small portion of the variance of the second grade SAT scores (1\% of the variance for reading and mathematics). They also accounted for $5 \%$ of the variance in first grade reading and 3\% in first grade 
mathematics. Kindergarten results proved divisive in that there was no relationship between the DECA and reading but the DECA did account for $4 \%$ of the kindergarten math grades. This finding is similar to the findings of previous research which found that social and emotional development can predict later academic success (Agostin \& Bain, 1997; Burchinal, Peisner-Feinberg, Pianta, \& Howes, 2002; Normandeau \& Guay, 1998; Pianta \& Harbers, 1996; Shoda, Mischel, \& Peake, 1990; Slaughter-Defoe \& Rubin, 2001; Smith \& Walden, 2001; Stipek, 1993; Turner \& Johnson, 2003). Similar to the findings of Turner and Johnson (2003) the results of this study may seem minimal and irrelevant, yet after accounting for many variables (academic achievement, language, and socioeconomic status) in a child's life, social and emotional development does play a role in a child's academic success.

While the DECA factors are not predictors of second and third grade academic success, there is a critical and indirect effect of the DECA on academic success. The DECA accounts for a minimal portion of kindergarten and first grade academic success. As noted in the results, previous academic success is the main predictor for academic achievement in second and third grade. Therefore, if the DECA influences the end of the year academic grades in kindergarten and first grade, it indirectly predicts the students' future scores.

Reynolds (1989) found that initiative had the greatest influence on the academic success of first graders in mathematics. However, the results of the current study show that the three DECA factors have the greatest predictive value on first grade reading. This could be the result of children having to display tremendous self-control while reading and answering questions as well as during teacher read-aloud sessions in which 
the children are asked to sit quietly and pay attention while the teacher reads. Another reason could be the result of children's persistence when trying to learn to read. Similar to trying to solve a puzzle, children who are learning to read are trying to solve the phonics puzzle. Burchinal, Peisner-Feinberg, Pianta, and Howes (2002) had similar results regarding attachment; in that a student's academic success in reading was predicted by the relationship between the student and teacher. However, the current study showed that attachment had the greatest relationship with kindergarten mathematics end of the year grades.

In kindergarten, however, the results showed the DECA to significantly predict mathematics grades as opposed to reading. One reason for this finding may be the fact that reading in kindergarten can be related to language development and many of these children do not yet speak English, even though language was accounted for. Another reason may be the use of manipulatives when teaching kindergarten math which allows students the ability to take initiative and remain in control while using these manipulatives and completing hands-on activities.

Even though the effect sizes may be low, the fact that they exist at all suggests that this line of inquiry deserves more study. The difficulty in trying to connect social and emotional development with academic or scholastic outcomes lies partly in the vagueness of social and emotional behavior. Whereas academic outcomes are easily quantified, behaviors lend themselves more to descriptions and anecdotes. The DECA is one the most successful measures being used but it too has its limitations. The current definitions (initiative, self-control, and attachment) are useful but may not be exact. Also the measures that are used to detect them may not be sensitive enough as yet to capture 
the true constructs of social and emotional development that most educators still believe significantly predict children's school performance (Johnson, Gallagher, Cook, \& Wong, 1995; Lin, Lawrence, \& Gorrell, 2003; McAllister, Wilson, Green, \& Baldwin, 2005;

Piotrkowski, Botsko, \& Matthews, 2000; Wesley \& Buysse, 2003)

Implications

This study found that social and emotional development plays a minimal but critical indirect role in the academic achievement of Hispanic children from low-income families. These findings lead to a couple of implications which early childhood educators should take into account.

The first implication involves the importance of assessing social and emotional development among young children. Early childhood educators have long touted the academic benefits of social and emotional development (i.e., better attention, neater work, less impulsivity), but it may be that social and emotional development may be mostly good for developing well-mannered and behaved children, and largely irrelevant to academic outcomes measured by standardized tests. This would not be a complete tragedy but would caution against overselling one type of behavior as an antidote for another.

The findings of this study also demonstrated that although the DECA factors did not account for any significant variance in second and third grade, they did account for a small portion of the variance in kindergarten and first grade. Since the main predictor of future academic success was previous academic achievement, it is safe to say that social and emotional development does indirectly predict those scores in second and third grade. The second implication then is that social and emotional development should best 
be addressed during the primary years when it will most predict early learning. Curriculums regarding play allow children to develop these essential social and emotional skills; which will later indirectly predict their academic success.

Even though this study was not able to confirm the existence of a long term link between social and emotional development and later academic success that should not be taken as an indictment of social and emotional development. The idea that preschool age children gain knowledge through social and emotional interactions (usually related to play) is well established and data supporting it is unassailable. In fact others are finding tremendous success (Bodrova \&Leong, 2003) in socially mediated curricula heavy on child directed play.

Bodrova and Leong (2007) have established a "learn by doing" approach to education in which play is an integral part. Taking ideas from Vygotsky and Piaget among others, they developed Tools of the Mind, a play based curriculum that stresses how learning takes place when play is properly used. In order to use play, teachers must first find the students' zone of proximal development-which will then allow the teacher to know at what level of development the student is learning. The teacher then becomes a mediator helping the students solve problems and perform independently. The mediator also promotes the students' thinking from lower cognitive thinking to higher cognitive thinking. The teachers should actively use language as an agent for culture, allowing children to develop a language that is most resourceful to them. Finally, teachers must take part in the shared activities of the children while they play. This is how the children learn by playing. Teachers must participate during the child's play especially when they see questions arise that can be easily answered through more play. Maybe they will be 
able to find the link between social and emotional development that this study, with its limitations, was not able to.

\section{Areas for Future Research}

This study attempted to scale a very high wall with too small a latter as it turned out. The population used was large but homogenous (poor and Hispanic) limiting the amount of variance. Much of the variance of the predictor variables was accounted for by other constants. Thererfore, the effect size would have had to have been large for the associations to show up all the way into the third grade. This does not mean that this type of analysis should be abandoned. Even though this study suggests that the link may be small, others should continue to look for connections between these two separate developmental levels using better data bases and more sophisticated measures.

The social and emotional constructs of initiative, attachment, and self-control exist in all populations, but they manifest themselves in unique ways depending upon cultural norms. Hispanic children from low-income families were chosen in order to find if social and emotional development predicts the academic achievement in children of the fastest growing ethnic group in the United States. The lack of research found on this group of students makes this study significant in that it is one of the first of its kind.

One area of interest for future research would be to study the profiles of other racial and cultural groups to determine if those results are consistent or differ with the results from the current study. It would also be of interest to compare the DECA scores of different racial or ethnic groups and within racial or ethnic groups to note similarities and differences. For example, within the Hispanic culture there are subgroups of people from different countries that consider themselves different from those of other countries. 
The same is true for Blacks; those from the Caribbean Islands consider themselves a different culture than Blacks from the United States or directly from Africa. This would add support to the idea that social and emotional development is not culturally neutral but is an interaction between the child and society.

A second topic of interest for further research is how the total protective factors score (a combination of the three factors addressed in this study) of the DECA is related to academic achievement. The behavioral concerns component of the DECA can also be used to analyze if it inversely predicts a child's academic achievement. Again, results can be compared across cultural and racial groups in order to determine if there is a difference in the social and emotional development and academic achievement across groups.

Finally, there is a group of students in each class invariably labeled as shy or disconnected by teachers and classmates. These students may not exhibit social inhibitions, behavior problems or initiative but they may be in danger of falling behind academically because they are forgotten in the classroom. (Fantuzzo, Bulotsky, McDermott, Mosca, \& Lutz, 2003; Fantuzzo \& McWayne, 2002). These children show great self-control because they do not want to draw attention to themselves. It is important to conduct additional research on children who may fall through the cracks because they do not call attention to themselves negatively by disrupting the class or excel academically above all the other children in the class. These shy and disconnected students receive average grades and test scores and they have few friends. As the years progress their grades and test scores may begin to suffer but teachers do not notice since they do not draw attention to themselves. 


\section{Limitations}

The first limitation in the study was the homogeneous sample of Hispanic children from low-income families in one urban city. The fact that the sample was so specific does not allow for the generalization of results among other groups of children or across other geographic areas of the United States. This study only focused on such a specific group because of the limited research on this fast growing ethnic minority group.

The second limitation was the high degree of correlation between the three DECA factors. This high correlation between the factors did not allow for the true predictive value of the DECA on academic success to emerge. The total protective factors score should have been used to account for the variance. However, this score was not used because this study was looking specifically at how each of the three factors worked independently. This study intended to examine if one of the factors was able to predict better than the others. The results revealed that when there was a significant predictive value of the DECA, initiative had the highest predictive value with Hispanic children from low-income families.

\section{Summary}

The current trend of high-stakes testing has taken a toll on young children's social and emotional development. The primary purpose of this study was to determine the relationships between prekindergarten students' social and emotional development and later academic achievement. Hispanic children from low-income families were followed from prekindergarten through third grade. Hierarchical regressions showed that social and emotional development is a small yet significant predictor of academic achievement among Hispanic children, specifically in first grade and kindergarten mathematics. 


\section{REFERENCES}

Aber, J. L., \& Allen, J. P. (1987). Effects of maltreatment on young children's socioemotional development: An attachment theory perspective. Developmental Psychology, 23(3), 406-414.

Agostin, T. M., \& Bain, S. K. (1997). Predicting early school success with developmental and social skills screeners. Psychology in the Schools, 34(3), 219228 .

Ainsworth, M. D. S. (1992). A consideration of social referencing in the context of attachment theory and research. In S. Feinman (Ed.), Social referencing and the social construction of reality in infancy (pp. 349-367). New York, NY: Plenum Press.

Ainsworth, M. D. S. \& Bowlby, J. (1991). An ethological approach to personality development. American Psychologist, 46, 331-341.

Amabile, T. M., \& Hennesey, B. A. (1992). The motivation for creativity in children. In A. K. Boggiano \& T. S. Pittman (Eds.), Achievement and motivation. New York, NY: Cambridge University Press.

Andreassen, C. \& West, J. (2007). Measuring socioemotional functioning in a national birth cohort study. Infant Mental Health Journal, 28(6), 627-646.

A Nation at Risk. (1983). Retrieved October23, 2003, from www.ed.gov/pubs/NatAtRisk/risk

Bandura, A. (1977). Social learning theory. Englewood Cliffs, NJ: Prentice-Hall.

Bandura, A. (1986). Social foundations of thought and action: A social cognitive theory. Englewood Cliffs, NJ: Prentice-Hall

Bandura, A. (1989). Human Agency in social cognitive theory. American Psychologist, 44(9), $1175-1184$.

Bandura, A. (1992). Social cognitive theory of social referencing. In S. Feinman (Ed.), Social referencing and the social construction of reality in infancy (pp. 175-208). New York: Plenum Press.

Bandura, A. (1997). Self-efficacy: The exercise of control. New York: Freeman.

Bandura, A. (2000). Exercise of human agency through collective efficacy. Current Directions in Psychological Science, 9, 75-78. 
Bandura, A. (2001). Social cognitive theory: An agentic perspective. Annual Review of Psychology, 52, 1-26.

Bandura, A. (2006). Toward a psychology of human agency. Perspectives on Psychological Science, 1(2), 164-180.

Bandura, A., \& Mischel, W. (1965). Modification of self-imposed delay of reward through exposure to live and symbolic models. Journal of Personality and Social Psychology, 2(5), 698-705.

Barbarin, O., Bryant, D., McCandies, T., Burchinal, M., Early, D., Clifford, R., Pianta, R., \& Howes, C. (2006). Children enrolled in public pre-k: The relation of family life, neighborhood quality, and socioeconomic resources to early competence. American Journal of Orthopsychiatry, 76(2), 265-276.

Beatty, B. (1995). Preschool education in America: The culture of young children from the colonial era to the present. New Haven, CT., Yale University Press

Bell, S. M., \& Ainsworth, M. D. S. (1972). Infant crying and maternal responsiveness. Child Development, 43, 1171-1190.

Bodrova, E., \& Leong, D. J. (2003). The importance of being playful. Educational Leadership, 60(7), 50-53.

Bodrova, E., \& Leong, D. J. (2007). Tools of the mind ( $2^{\text {nd }}$ ed.). Upper Saddle River, NJ: Pearson Education, Inc.

Borg, W. R. \& Gall, M. D. (1971). Educational research: An introduction. New York: David McKay Company.

Bowlby, J. (1969). Attachment and loss (Vol. 3). New York, NY: Basic Books.

Bronfenbrenner, U. (1979). The ecology of human development. Cambridge, MA: Harvard University Press.

Bronfenbrenner, U., \& Morris, P. A. (1998). The ecology of developmental processes. In W. Damon \& R. Lerner (Eds), Handbook of child psychology: Volume 1:

Theorectical models of human development (5th ed.) (pp. 993-1028). Hoboken, NJ: John Wiley \& Sons.

Brookhart, S. M. (1993). Teachers' grading practices: Meaning and values. Journal of Educational Measurement, 30(2), 123-142. 
Burchinal, M. R., Peisner-Feinberg, E., Pianta, R., \& Howes, C. (2002). Development of academic skills from preschool through second grade: Family and classroom predictors of developmental trajectories. Journal of School Psychology, 40, 415436.

Bursuck, W. D., Polloway, E. A., Plante, L., Epstein, M. H., Jayanthi, M., \& McConeghy, J. L.(1996). Report card grading and adaptations: A national survey of classroom practices. Exceptional Children, 62(4), 301-318.

Carlton, M. P., \& Winsler, A. (1999). School readiness: The need for a paradigm shift. School Psychology Review, 28, 338-352.

Carney, R. N. (2004). Review of the Stanford Achievement Test, Tenth Edition. In J.C. Impara \& B.S. Plake (Eds.), The Sixteenth Mental Measurements Yearbook (pp. 969-972). Lincoln, NE: The Buros Institute of Mental Measurements.

Chang, F., \& Burns, B. M. (2005). Attention in preschoolers: Associations with effortful control and motivation. Child Development, 76(1), 247-263.

Coolahan, K. Fantuzzo, J., Mendez, J., \& McDermott, P. (2000). Preschool peer interactions and readiness to learn: Relationships between classroom peer play and learning behaviors and conduct. Journal of Educational Psychology, 92(3), 458-465.

Cooper, J. L., Masi, R., \& Vick, J. (2009). Social-emotional development in early childhood: What every policymaker should know. Retrieved January 10, 2010 from Columbia University, National Center for Children in Poverty Web site: http://www.nccp.org/publications/pdf/text_882.pdf

Davis, M. R. (2005, September 28). House oks Head Start reauthorization. Education Week, p. 25

Delpit, L. D. (1995). Other people's children: Cultural conflict in the classroom. New York, NY: New Press.

Dinan, K. A. (2006). Young children in immigrant families. Retrieved on March 26, 2010, from nccp.org/publications/pub_661html

Dumka, L.E., Gonzales, N. A., Bonds, D. D., \& Millsap, R. E. (2009). Academic success of Mexican origin adolescent boys and girls: The role of mothers and fathers parenting and cultural orientation. Sex Roles, 60(7-8), 588-599.

Duncan, G.J., Claessens, A., Huston, A., Pagani, L.S., Engel, M., Sexton, H., et al. (2007).School readiness and later achievement. Developmental Psychology, 43(6), 1428-1446. 
Eamon, M. K., \& Mulder, C. (2005). Predicting antisocial behavior among Latino young adolescents: AN ecological systems analysis. American Journal of Orthopsychiatry, 75(1), 117-127.

Early, D. M., Maxwell, K. L., Burchinal, M., Alva, S., Bender, R. H., Bryant, D., et al. (2007). Teachers' education, classroom quality, and young children's academic skills: Results from seven studies of preschool programs. Child Development 28(2), $558-580$.

Elkind, D. (2001). The hurried child; Growing up too fast too soon. Cambridge, MA; Perseus Publishing.

Epstein, H. M. (1998). Behavioral and Emotional Rating Scale. FL: Psychological Assessment Resources, Inc.

Erikson, E. H. (1950). Childhood and society. New York: W. W. Norton.

Fantuzzo, J., Bulotsky, R., McDermott, P., Mosca, S., \& Lutz, M. N. (2003). Multivariate analysis of emotional and behavioral adjustment and preschool educational outcomes. School Psychology, 2, 185-203.

Fantuzzo, J. \& McWayne, C. (2002). The relationship between peer-play interactions in the family context and dimensions of school readiness for low-income preschool children. Journal of Educational Psychology, 1, 79-87.

Florida Department of Children and Families (2009). Temporary Assistance for Needy Families (TANF) Information. Retrieved July 15, 2009 from www.dcf.state.fl.us/ess/tanweb.shtnl

Florida Department of Education (2007). Assessment and accountability briefing book. Tallahassee, FL: Author.

Ford, M. (1992). Motivating humans. New York, NY: Sage.

Ford, M. (1996). Motivational opportunities and obstacles associated with social responsibility and caring behavior in school contexts. In J. Juvonen \& K. R. Wentzel (Eds.), Social motivation: Understanding children's school adjustment. New York: Cambridge University Press.

Gamble, W. C., \& Modry-Mandell, K. (2008). Family relations and the adjustment of young children of Mexican descent: Do family cultural values moderate these associations. Social Development, 17(2), 358-379.

Gesell, A \& Ilg, F. L. (1949). Child development: An introduction to the study of human growth. New York: Harper \& Row. 
Goals 2000: Educate America Act. (1994). Retrieved October 23, 2003 from www.negp.gov

Hall, E. T. (1976). Beyond culture. Garden City, NJ: Anchor Press/Doubleday.

Harcourt Brace. (2003). Stanford Achievement Test (10 ${ }^{\text {th }}$ ed.). Technical Data Report. San Antonio, TX: Author.

Harmon, M., Smith, T. A., Martin, M. O., Kelly, D. L., Beaton, A. E., Mullis I. V. S., Gonzalez, E. J., \& Orpwood, G. (1997). Performance assessment in IEA's Third International Mathematics and Science Study. Retrieved on January 11, 2010 from Boston College, TIMSS International Study Center Web site: http://timss.bc.edu/timss1995i/PAreport.html

Heaviside, S., Farris, E., \& Carpenter, J. (1993). Public school kindergarten teachers' views of children's readiness for school. Washington, D. C.: U. S. Department of Education, NCES (NCES93-410).

Hill, N. E. (2001). Parenting and academic socialization as they relate to school readiness: The roles of ethnicity and family income. Journal of Educational Psychology, 93(4), 686-697.

Howes, R. B., Lange, G., Farran, D. C., \& Boyles, C. D. (2003). Motivation and selfregulation as predictors of achievement in economically disadvantaged young children. The Journal of Experimental Education, 71(2), 151-174.

Howes, C., Burchinal, M., Pianta, R., Bryant, D., Early, D., Clifford, R., \& Barbarin, O. (2008). Ready to learn? Children's pre-academic achievement in pre-kindergarten programs. Early Childhood Research Quarterly, 23(1), 27-50.

Jaberg, P. E., Dixon, D. J., \& Weiss, G. M. (2009). Replication evidence in support of the psychometric properties of the Devereux Early Childhood Assessment. Canadian Journal of School Psychology, 24(2), 158-166.

Janus, M., \& Offord, D. R. (2007). Development and psychometric properties of the Early Development Instrument (EDI): A measure if children's school readiness. Canadian Journal of Behavioural Science, 39(1), 1-22.

Johnson, L. J., Gallagher, R. J., Cook, M., \& Wong, P. (1995). Critical skills for kindergarten: Perceptions from kindergarten teachers. Journal of Early Intervention, 19, 315-349.

Kaiser, B., \& Rasminsky, J. S. (2003). Challenging behavior in young children: Understanding, preventing and responding effectively. Boston: MA, Pearson Education. 
Kurdek, L. A., \& Sinclair, R. J. (2001). Predicting reading and mathematics achievement in fourth grade from kindergarten readiness scores. Journal of Educational Psychology, 93(3), 451-455.

Ladd, G. W., Kochenderfer, B. J., \& Coleman, C. C. (1996). Friendship quality as a predictor of young children's early school adjustment. Child Development, 67, 1103-1118.

LeBuffe, P. A., \& Naglieri, J. A. (1998). The Devereux Early Childhood Assessment $(D E C A)$. Villanova, PA: Devereux Foundation.

LeBuffe, P. A., \& Naglieri, J. A. (2009). The Devereux Early Childhood Assessment (DECA): A measure of within-child protective factors in preschool children. Retrieved March 16, 2009 from www.devereux.org

LeBuffe, P. A., \& Shapiro, V. B. (2004). Lending "strength" to the assessment of preschool social-emotional health. The California School Psychologist, 9, 51-61.

Leedy, P. D., \& Ormond, J. E. (2005). Practical research: Planning and design $\left(8^{\text {th }}\right.$ edition). Upper Saddle, NJ: Pearson Merrill Prentice Hall.

Lin, H-L., Lawrence, F. R., \& Gorrell, J. (2003). Kindergarten teacher's views of children's readiness for school. Early Childhood Research Quarterly, 18, 225237.

Lindsey, E. W. (2002). Preschool children's friendships and peer acceptance: Links to social competence. Child Study Journal, 32(3), 145-155.

Loukas, A., Prelow, H. M., Suizzo, M., \& Allua, S. (2008). Mothering and peer associations mediate cumulative risk effects for Latino youth. Journal of Marriage and Family, 70(1), 76-85.

Loukas, A., Suizzo,M., \& Prelow, H. M. (2007). Examining resource and protective factors in the adjustment of Latino youth in low income families: What role does maternal acculturation play? Journal of Youth and Adolescence, 36(4), 489-501.

Lynch, E. W. (1998). Developing cross-cultural competence. In E. W. Lynch \& M. J. Hanson (Eds.), A guide for working with children and their families: developing cross-cultural competence, (pp. 47-86). Baltimore, MD: Paul H. Brookes Publishing Company.

Lyons, J. S., Griffin, E., \& Fazio, M. (1999). Child and Adolescent Needs and Strengths (CANS): An information and integration tool for children and adolescents with mental health challenges. Chicago, IL: Buddin Praed Foundation. 
Magnuson, K. A., Meyers, M. K., Ruhm, C. J., \& Waldfogel, J. (2004). Inequality in preschool education and school readiness. American Educational Research Journal, 41(1), 115-157.

Malakoff, M. E., Underhill, J. M., \& Zigler, E. (1998). Influence of inner-city environment and Head Start experience on effectance motivation. American Journal of Orthopsychiatry, 68(4), 630-638.

Mantzicopoulos, P. (2003). Flunking kindergarten after Head Start: An inquiry into the contribution of contextual and individual variables. Journal of Educational Psychology, 95, 268-278.

Marsh, H. W., \& Yeung, A. S. (1997). Causal effects of academic self-concept on academic achievement: Structural equation models of longitudinal data. Journal of Educational Psychology, 89, 41-54.

May, D. C., \& Kundert, D. K. (1997). School readiness practices and children at-risk: Examining the issues. Psychology in the Schools, 34, 73-84.

McAllister, C. L., Wilson, P. C., Green, B. L., \& Baldwin, J.L. (2005). "Come and take a walk": Listening to Early Head Start parents on school-readiness as a matter of child, family and community health. American Journal of Public Health, 95(4), 617-625.

McClelland, M.M., \& Morrison, F.J. (2003). The emergence of learning-related social skills in preschool children. Early Childhood Research Quarterly, 18, 206-224.

Meisels, S. J. (1998). Assessing Readiness (Repot No. CIERA-R-3-002). Ann Arbor, MI: Center for the Improvement of Early reading Achievement. (ERIC Document Reproduction Service No. ED429272)

Meisels, S. J. (1999). Assessing readiness. In R. C. Pianta \& M. J. Cox (Eds.), The transition to kindergarten (pp. 39-66). Baltimore, MD: Paul H. Brookes Publishing Co.

Mendez, J. L., \& Fogle, L. M. (2002). Parental reports of preschool children's social behavior: Relations among peer play, language competence and problem behavior. Journal of Psychoeducational Assessment, 20, 370-385.

Miller, E., \& Almon, J. (2009). The crisis in kindergarten: Why children need to play in school. Retrieved September 16, 2009 from Alliance for Childhood Web site www.allianceforchildhood.org 
Miller, H. V., Jennings, W. G., Alvarez-Rivera, L. L., \& Lanza-Kaduce, L. (2009). Selfcontrol, attachment and deviance among Hispanic adolescents. Journal of Criminal Justice, 37, 77-84.

Mischel, W. (1979). On the interface of cognition and personality: Beyond the personsituation debate. American Psychologist, 34(9), 740-754.

Mischel, W., \& Ebbesen, E. B. (1970). Attention in delay of gratification. Journal of Personality and Social Psychology, 16(2), 329-337.

Mischel, W., \& Patterson, C. J. (1976). Substantive and structural elements of effective plans for self-control. Journal of Personality and Social Psychology, 34(5), 942950 .

Morse, D. T. (2004). Review of the Stanford Achievement Test, Tenth Edition. Review of the Stanford Achievement Test, Tenth Edition. In J.C. Impara \& B.S. Plake (Eds.), The Sixteenth Mental Measurements Yearbook (pp. 969-972). Lincoln, NE: The Buros Institute of Mental Measurements.

Naglieri, J. A., LeBuffe, P. A., \& Pfeiffer, S. I. (1994). Devereux Scales of Mental Disorders. San Antonio, TX: The Psychological Corporation.

No Child Left Behind. (2001). Retrieved on April 4, 2003, from www.nclb.gov/next/overview/index.html

Normandeau, S., \& Guay, F. (1998). Preschool behavior and first grade school achievement: The mediational role of cognitive self-control. Journal of Educational Psychology, 90(1), 111-121.

O'Connor, E., \& McCartney, K. (2007). Examining teacher-child relationships and achievement as part of an ecological model of development. American Educational Research Journal, 44(2), 340-369.

Patterson, C. J., \& Mischel, W. (1975). Plans to resist distraction. Developmental Psychology, 11(3), 369-378.

Peacock, M. J., McClure, F., \& Agars, M. D. (2003). Predictors of delinquent behaviors among Latino youth. Urban Review, 35(1), 59-72.

Piaget, J. (1962). Play, dreams, and imitation in childhood. New York: Norton.

Pianta, R. C., \& Harbers, K. L. (1996). Observing mother and child behavior in a problem solving situation at school entry: Relations with academic achievement. Journal of School Psychology, 34(3), 307-322. 
Pianta, R. C., \& Stuhlman, M. W. (2004). Teacher-child relationships and children's success in the first years of school. School Psychology Review, 33(3), 444-458.

Piotrkowski, C. S., Botsko, M., \& Matthews, E. (2000). Parents' and teachers' beliefs about children's school readiness in a high need community. Early Childhood Research Quarterly, 15, 537-558.

Polloway, E. A., Epstein, M. H., Bursuck, W. D., Roderique, T. W., McConeghy, J. L., \& Jayanthi, M. (1994). Classroom grading: A national survey of policies. Remedial and Special Education, 15, 162-170.

Randall, J., \& Engelhard, G. (2009a). Differences between teachers' grading practices on elementary and middle schools. Journal of Educational Research, 102(3), 175-185.

Randall, J., \& Engelhard, G. (2009b). Examining teacher grades using Rasch Measurement Theory. Journal of Educational Measurement, 46(1), 1-18.

Reynolds, A. J. (1989). A structural model of first grade outcomes for an urban, low socioeconomic status, minority population. Journal of Educational Psychology, 81(4), 594-603.

Rim-Kaufman, S. E., Pianta, R. C., \& Cox, M. J. (2000). Teachers' judgements of problems in the transition to kindergarten, Early Childhood Research Quarterly, 15(2), 147-166.

Rosas, S., Chaiken, M. S. W., \& Case, M. S. (2007). Devereux Early Childhood Assessment ratings from parents and teachers in Deleware. Retrieved February 9, 2010 from http://staticnemours.org/www-filebox/nhps/deca.pdf

Ross, J. A., \& Gray, P. (2008). Alignment of scores on large scale assessments and report card grades. Alberta Journal of Educational Research, 54(3), 327-341.

Santrock, J. W. (2004). Child Development. Boston, MA: McGraw Hill.

Shade, B. J., Kelly, C., \& Oberg, M. (1997). Creating culturally responsive classrooms. Washington, D.C: American Psychological Association.

Shepard, L. A. (1997). Children not ready to learn? The invalidity of school readiness testing. Psychology in the Schools, 34(2), 85-97

Shoda, Y., Mischel, W., \& Peake, P. K. (1990). Predicting adolescent cognitive and selfregulatory competencies from preschool delay of gratification: Identifying diagnostic conditions. Developmental Psychology, 26(6), 978-986. 
Shonkoff. J. P., \& Phillips, D. A. (Eds.) (2000). From neurons to neighborhoods: The science of early childhood development. Committee on integrating the Science of Early Childhood Development, National research Council and Institute of Medicine. Washington, D.C: National Academy Press

Slaughter-Defoe, D. T. \& Rubin, H. H. (2001). A longitudical case study of Head Start eligible children: Implications for urban education. Educational Psychologist, $36(1), 31-44$.

Smith, M. \& Walden, T. (2001). An exploration of African American preschool-aged children's behavioral regulation in emotionally arousing situations. Child Study Journal, 31(1), 13-43.

Spieker, S. J., Nelson, D. C., Petras, A., Jolley, S. N., \& Barnard, K. E. (2003). Joint influence of childcare and infant attachment security for cognitive and language outcomes of low income toddlers. Infant Behavior and Development, 26, 326344.

Sroufe, L. A. (1983). Infant-caregiver attachment and patterns of adaptation in preschool: The roots of maladaptation and competence. In M. Perlmutter (Ed.), Minnesota Symposium in child psychology (pp. 41-83). Hillsdale, NJ: Erlbaum Associates.

Stevens, T., Olivarez, Jr., A., \& Hamman, D. (2006). The role of cognition, motivation and emotion in explaining the mathematics achievement gap between Hispanic and white students. Hispanic Journal of Behavioral Sciences, 28(2), 161-186.

Stipek, D. (1993). Motivation to learn: From theory to practice. Needham Heights, MA: Allyn \& Bacon.

Stipek, D., \& Ryan, R. H. (1997). Economically disadvantaged preschoolers: Ready to learn but further to go. Developmental Psychology, 33(4), 711-723.

Tabachnick, B. G., \& Fidell, L. S. (2001). Using miltivariate statistics. Boston, MA: Allyn and Bacon.

Tashakkori, A., \& Teddlie, C. (1998). Mixed methodology: Combining qualitative and quantitative approaches. Thousand Oaks, CA: Sage.

Thompson, R. A., \& Raikes, H. A. (2007). The social and emotional foundations of school readiness.. In J. KNitzer, R. Kaufmann, \& D. Perry (Eds). Social and emotionalhealth in early childhood: Building bridges between services and systems. Baltimore MD: Paul Brookes Publishing Co. 
Tomlinson, C. A. (2001). Grading for success. Educational Leadership, 58(6), 12-15.

Turner, L. A., \& Johnson, B. (2003). A model of mastery motivation for at-risk preschoolers. Journal of Educational Psychology, 95(3), 495-505.

U.S. Census Bureau. (2009). Quick Facts. Retrieved June 15, 2009, from http://www.census.gov/main/www/cen2000

Vygotsky, L. (1978). Mind in society: The development of higher psychological processes. Cambridge, MA: Harvard University Press.

Wesley, P. W., \& Buysse, V. (2003). Making meaning of school readiness in schools and communities. Early Childhood Research Quarterly, 18, 351-375.

Winsler, A., Tran, H., Hartman, S. C., Madigan, A. L., Manfra, L., \& Bleiker,C. (2008). School readiness gains made by ethnically diverse children in poverty attending center-based childcare and public school prekindergarten programs. Early Childhood Research Quarterly, 23, 314-329.

Yates, B. T., \& Mischel, W. (1979). Young children's preferred attentional strategies for delaying gratification. Journal of Personality and Social Psychology, 37(2), 286300 .

Zigler, E. (1995). Meeting the needs of children in poverty. American Journal of Orthopsychiatry, 65(1), 6-9.

Zigler, E. (1999). Head Start is not child care. American Psychologist,54(2), 142.

Zigler, Edward F., \& Bishop-Josef, Sandra J.(2006) The cognitive child versus the whole child: Lessons from 40 years of head start. In, D. G. Singer, R. M. Golinkoff, \& K. Hirsh-Pasek (Eds). Play = learning: How play motivates and enhances children's cognitive and social-emotional growth (pp. 15-35). New York: Oxford University Press.

Zimmerman, B. J. \& Schunk, D. H. (2001). Self-regulated learning and academic achievement: Theoretical perspectives. Mahwah, NJ: Lawrence Earlbaum Associates, Inc.

Zuniga, M. E. (1998). Families with Latino roots. In E. W. Lynch \& M. J. Hanson (Eds.), A guide for working with children and their families: Developing crosscultural competence, (pp. 47-86). Baltimore, ML: Paul H. Brookes Publishing Company.

Zuniga, S. A., \& Howes, C. (2009). Predictions of children's experiences with Latina family child care providers. Early Education and Development, 20(2), 265-284. 
VITA

CHRISTINA MORE MUELLE

May 16, 1977

1999

2000

2000-2004

2002

2004

2004-2005

2005-2006
Born - South Miami, Florida

BA, Education

University of Florida

Gainesville, Florida

MA, Education

University of Florida

Gainesville, Florida

Kindergarten Teacher

Mater Academy Charter School

Miami, Florida

Program Coordinator

Chapel Hill Outreach Training Project

Miami, Florida

Curriculum Designer

Early Childhood Development Track

Alternative Licensure Bachelor Degree

College of Education

Florida International University

Miami, Florida

Graduate Assistant

EMBERS Program

College of Education

Florida International University

Miami, Florida

Assistant Director

Early Beginnings Academy Charter School

Miami, Florida

Adjunct Instructor

College of Education

Florida International Uninversity

Miami, Florida 
Grant Writer

Florida International University

College of Education

Project Heat -awarded $\$ 750,000$

2006-present

Teacher

Henry M. Flagler Elementary School

Miami, Florida

\section{PUBLICATIONS AND PRESENTATIONS}

More-Muelle, C. (2005). The history of kindergarten from a critical perspective. Paper presented at the College of Education Research Conference, Florida International University, Miami, FL.

More-Muelle, C. (2005). Assessment of preschoolers using the LAP-D and DECA. Miami, FL: Early Beginnings Academy.

More-Muelle, C. (2004). Using the ELAP with infants and toddlers. Miami, FL: Presentation to the graduate council, Florida International University.

More-Muelle, Christina, (2010) The impact of social development on school readiness: A theoretical perspective. Unpublished manuscript.

More-Muelle, Christina, (2005) _The homogenizing force of kindergarten: Americanization at the turn of the $20^{\text {th }}$ century. Unpublished manuscript. 